\title{
Os efeitos da criação de leis de meia entrada para estudantes sobre o consumo de bens e serviços culturais no Brasil *
}

\author{
Marcos Vinicio Wink Junior \\ Pesquisador - Fundação de Economia e Estatística \\ Endereço: Rua Duque de Caxias, 1691 - Porto Alegre/RS \\ CEP: $90010-283$ - E-mail: marcos@fee.tche.br \\ Felipe Garcia Ribeiro \\ Professor - Universidade Federal de Pelotas (UFPel) \\ Endereço: Rua Gomes Carneiro, 1 - Pelotas/RS \\ CEP: 96001-970 - E-mail: felipe.garcia.rs@gmail.com

\section{Stefano Florissi} \\ Professor - Universidade Federal do Rio Grande do Sul (UFRGS) \\ Endereço: Av. João Pessoa, 52 - Porto Alegre/RS \\ CEP: 90040-000 - E-mail: florissi@portoweb.com.br

\section{Pedro Tonon Zuanazzi} \\ Pesquisador - Fundação de Economia e Estatística \\ Endereço: Rua Duque de Caxias, 1691 - Porto Alegre/RS \\ CEP: 90010-283 - E-mail: pedro@fee.tche.br
}

Recebido: 03/03/2015. Aceite 01/08/2016.

\section{Resumo}

Este trabalho estima os efeitos da implementação de leis de meia entrada sobre o consumo de bens e serviços culturais dos estudantes brasileiros, utilizando as amostras coletadas para todas as regiões metropolitanas pelas Pesquisas de Orçamento Familiar (POF), realizadas em 1987/88, 1995/96, 2002/03 e 2008/09. Avaliam-se os efeitos das leis tanto sobre a proporção de estudantes consumidores de cultura, quanto sobre os gastos dos estudantes com esse tipo de serviço. Para estimar a possível relação causal existente, exploram-se as diferentes datas de criação das leis da meia entrada entre os estados brasileiros, utilizando-se as metodologias de Diferenças-em-Diferenças (DD) e Diferenças Triplas (DDD). Os resultados encontrados no presente trabalho sugerem que as leis de meia entrada tiveram impactos positivos tanto em termos de aumento na probabilidade de os estudantes consumirem bens e serviços culturais, quanto em elevar seus gastos com cultura.

\section{Palavras-Chave}

Economia da cultura. Leis de meia entrada. Avaliação de política pública.

\footnotetext{
- Os autores agradecem aos participantes do $42^{\circ}$ Encontro Nacional de Economia pelas contribuições e aos pareceristas pelas sugestões. O primeiro autor agradece também à CAPES pelo suporte financeiro.
} 


\begin{abstract}
This paper estimates the effects of the laws of half price tickets on the consumption of cultural goods and services of Brazilian students using samples collected for all metropolitan regions from the Household Budget Surveys (HBS), carried out in 1987/88, $1995 / 96,2002 / 03$ and 2008/09. We evaluate the effects of the laws on the proportion of students that consume cultural services and changes in their expenses with those services. We explore the time differences of the creation of those laws among Brazilian states to estimate a causal relationship using the Difference-in-differences (DD) and Triple differences (DDD) methodology. We found that the laws of half price tickets had positive effects on increasing the likelihood that students consume cultural goods and services and on raising their spending with those goods and services.
\end{abstract}

\title{
Keywords
}

Cultural economics. Half price laws. Evaluation of public policy.

\section{JEL Classification}

Z1. Z18. D12

\section{Introdução}

Este trabalho tem por objetivo avaliar os efeitos da implementação das leis estaduais e municipais de meia entrada, criadas na década de noventa e nos anos dois mil, sobre o consumo de bens e serviços culturais dos estudantes. Para tanto, utilizam-se as amostras coletadas, para todas as regiões metropolitanas brasileiras, pela Pesquisa de Orçamento Familiar (POF) das edições de 1987/88, 1995/96, 2002/03 e 2008/09. Avaliam-se os efeitos da meia entrada tanto sobre a proporção de estudantes consumidores de cultura, quanto sobre os gastos dos estudantes com esse tipo de bem. Para avaliar a existência de uma possível relação causal da meia entrada e o consumo de cultura dos estudantes, exploram-se as diferentes datas de criação das leis entre os estados e municípios brasileiros, utilizandose as metodologias de Diferenças-em-Diferenças (DD) e Diferenças Triplas (DDD).

Os resultados obtidos sugerem que as leis de meia entrada tiveram efeitos positivos tanto em termos de aumento na probabilidade de os estudantes consumirem bens e serviços culturais quanto em elevação de gastos com esse tipo de bem e serviço. Encontram-se evidências também de que os efeitos das leis de meia entrada são heterogêneos entre os indivíduos, beneficiando principalmente a parcela da popu- 
lação mais jovem, com maior escolaridade e com maior renda. Os testes de robustez realizados neste trabalho, em geral, descartam a possibilidade de que o grupo dos não estudantes tenha sido afetado em termos de consumo de bens culturais pelas leis. Este é um ponto que suscita a necessidade de futuros trabalhos teóricos e empíricos sobre o assunto. É possível que o montante de repasse dos preços por parte das empresas para o grupo dos não estudantes, em consequência da existência de leis de meia entrada para os estudantes, seja uma função, por exemplo, do tamanho desses dois grupos no mercado de bens e serviços culturais. No caso em que a demanda dos não estudantes represente uma parcela significativa da demanda total, o repasse dos preços pode ser diluído nesse grupo.

Há diversos motivos que tornam a avaliação dos efeitos das leis de meia entrada relevante. Primeiro, no que concerne à teoria econômica, há toda uma tradição de pesquisa em Organização Industrial (OI) em estudar os efeitos das diferentes estratégias de discriminação de preços por parte das empresas para diferentes segmentos dos mercados. $\mathrm{O}$ interesse da pesquisa na área foca nas adversidades que as empresas podem enfrentar para implementação de estratégias de precificação baseadas na discriminação de preços entre grupos com diferentes demandas em relação aos bens e serviços. Avalia também os efeitos da discriminação de preços sobre os preços cobrados para cada grupo, quantidade de produto alocado em cada mercado, e os consequentes impactos sobre bem-estar (ver os clássicos SCHMALENSEE (1981); VARIAN (1985) e (HOLMES (1989)). Há ainda nessa área, além dos estudos teóricos, uma quantidade expressiva de trabalhos aplicados dedicados a avaliar empiricamente efeitos dessas estratégias de precificação (SHEPARD (1991); BORENSTEIN (1992); COHEN (2000) e McMANUS (2000)). Entretanto, não há nenhum estudo, sob nosso conhecimento, que avalie empiricamente efeitos de leis que "amarram" os preços cobrados a um grupo em preços cobrados a outros. Os resultados aqui obtidos, portanto, fornecem uma evidência diferente a literatura que pode balizar futuras pesquisas teóricas na área.

Ainda sobre esse primeiro ponto - estudos de OI - já existem trabalhos dedicados a estudar especificamente o mercado de bens e serviços culturais. Com pautas muito próximas daquelas da pesquisa tradicional em OI, esta linha está dedicada em entender as adversidades de implementação de diferentes estratégias de precifi- 
cação para grupos distintos e os impactos dessas diferentes estratégias no mercado de cultura (HUNTINGTON (1993) e COURTY e PAGLIERO (2012)). Assim, o presente estudo contribui também nessa área com uma investigação empírica dos efeitos de uma política cujo intuito é incentivar o consumo de bens e serviços culturais de um grupo específico do mercado através da alteração dos preços de equilíbrio.

Em segundo, a avaliação per si dos efeitos das leis de meia entrada interessa ao debate de políticas públicas. Primeiro, no Brasil, há outros mercados, serviços, que também são regulados por políticas e leis similares de preços diferenciados para estudantes em função do preço total cobrado. É o caso, por exemplo, do serviço de transporte público em diversas cidades do país. ${ }^{1}$ Assim, a avaliação aqui realizada sobre os efeitos das leis de meia entrada no consumo dos estudantes por bens e serviços culturais pode fornecer insights gerais do que ocorreria com a demanda de grupos beneficiados por políticas e leis similares em outros mercados e serviços.

Em terceiro, as leis de meia entrada são políticas que atingem uma população expressiva do país, portanto, seus impactos individuais podem repercutir em grandes consequências para o agregado. A dimensão do público-alvo das leis de meia entrada - a população de estudantes -, de acordo com dados do Censo Escolar de 2015 e do Censo da Educação Superior de 2014, é de aproximadamente 55 milhões de pessoas, o que corresponde a pouco mais de um quarto da população brasileira. O público potencialmente beneficiado é de tamanho similar ao do maior programa de transferência de renda condicionada do país: o Bolsa Família. ${ }^{2}$

Por fim, a avaliação da eficácia de políticas públicas (leis) que estimulem a demanda por cultura é importante também em decorrência do papel que a produção e o consumo de cultura podem exercer no processo de desenvolvimento humano e socioeconômico de regiões, municípios, estados e países. Segundo Throsby (1999), atividades culturais podem ser fundamentais para o desenvolvimento de uma região em função dos benefícios associados a ampliação do capital

1 A tarifa diferenciada de transporte público para os estudantes é regulada em cada município pelos órgãos responsáveis e empresas de transporte. Ver http://www.une.org.br/direitos-servicos./.

2 Para mais informações sobre cobertura do programa Bolsa Família ver http://mds.gov.br/ assuntos/bolsa-familia/dados. 
cultural de uma sociedade. Falck et al. (2011) também evidenciam o papel que o consumo de bens e serviços culturais podem desempenhar para a expansão do crescimento econômico e melhora nos indicadores de desenvolvimento humano e qualidade de vida. Entre os mecanismos que ligam cultura ao desenvolvimento econômico está o fato de que o consumo de cultura pode elevar a percepção das pessoas em relação aos benefícios da educação (LAREAU e HORVAT (1999) e FARKAS (2003)), que, como se sabe da literatura de crescimento econômico, ao menos tem uma correlação positiva importante com o padrão de vida das sociedades.

Assim, conforme exposto no parágrafo anterior, pode ser entendido que o consumo de cultura seja capaz de gerar uma externalidade positiva para a sociedade. Se um grupo de indivíduos tem uma baixa demanda pelo consumo da cultura, por quaisquer motivos, é possível que a quantidade consumida de cultura desse grupo esteja abaixo do nível socialmente desejável diante da presença de externalidades. Políticas que venham a estimular o consumo de cultura podem ser importantes para a promoção do desenvolvimento econômico. Em consequência, faz-se necessário a avaliação dessas políticas.

Além desta introdução, o trabalho conta com mais 4 seções. A seção 2 avalia os efeitos das leis de meia entrada sob a ótica da teoria econômica e das evidências já existentes na literatura. Discutem-se alguns trabalhos sobre os possíveis impactos de estratégias de regulamentação de preços com base no que se sabe sobre a demanda por bens e serviços culturais. Ainda na seção 2 são apresentados os benefícios da produção e do consumo de bens e serviços culturais documentados na pesquisa em economia da cultura. A seção 3 descreve os dados e a estratégia empírica utilizada. São discutidas as bases de dados e a forma como as POF's são utilizadas pela estratégia empírica deste estudo, que, como já dito, explora os diferentes momentos em que os estados e municípios do país passaram a implementar as leis de meia entrada para estudantes. Na seção 4 estão os resultados principais do trabalho. A seção 5 apresenta as considerações finais. 


\section{A Economia por trás das leis de meia entrada}

\subsection{Discriminação e regulamentação de preços}

As leis de meia entrada visam alterar os preços relativos de um grupo de consumidores, o de estudantes, de modo a incentivar seu consumo de bens e serviços culturais, mas com possíveis consequências sobre os preços relativos também dos não estudantes. Na prática, as leis forçam empresas a discriminar preços entre estudantes e não estudantes de acordo com a regra de que estudantes paguem metade do que pagam os não estudantes. Contudo, a prática de discriminação de preços entre grupos com demandas possivelmente diferentes (discriminação de preços de $3^{\circ}$ grau) pode ser posta em prática por empresas com algum poder de mercado e com capacidade de identificar os grupos com demandas diferentes sem a necessidade de nenhuma lei específica. O resultado conhecido da teoria econômica é que os preços cobrados são maiores para grupos com menores elasticidades-preço da demanda, e menores para os grupos com maiores elasticidades-preço da demanda.

Por se tratar de imposição do governo, as leis de meia entrada para estudantes não correspondem à clássica política de discriminação de preços de $3^{\circ}$ grau, uma vez que não são iniciativas das próprias empresas como estratégia para maximização de lucros. Dificilmente a regulamentação de preços via meia entrada coincidiria, em termos de preços cobrados, com as escolhas de firmas maximizadoras de lucros no cenário sem meia entrada. É bem possível que os lucros das empresas sejam menores no cenário com meia entrada.

Em relação aos efeitos sobre os consumidores, os impactos da lei dependem das elasticidades de preços da demanda. Se a demanda dos estudantes por bens culturais for relativamente mais elástica, a redução do preço ocasionaria um aumento mais que proporcional na demanda destes bens, podendo acarretar ampliação no consumo agregado de cultura. Tal reação depende também da elasticidade da demanda dos não estudantes que devem, com a imposição da lei, pagar preços superiores.

Nos últimos 20 anos desenvolveu-se extensa literatura empírica específica sobre discriminação de preços no mercado de bens e serviços culturais. As evidências apontam na direção de uma relação 
positiva entre receitas da firma e a adoção dessa prática, inclusive para bens culturais (Huntington (1993) e Courty e Pagliero (2012)).

Entretanto, os impactos de práticas de discriminação de preços sobre os consumidores não são claros, mas ambíguos. Leslie (2004) estima os efeitos de discriminação de preços de $2^{\circ}$ e $3^{\circ}$ graus, a partir de um modelo estrutural, para empresários e consumidores no mercado de ingressos de espetáculos da Broadway. Os resultados mostram que a discriminação de preços, via descontos de $50 \%$ no dia da apresentação, eleva o lucro das firmas em 5\%, em comparação com preços uniformes. Para os consumidores, no entanto, os ganhos de bem-estar são insignificantes, havendo apenas uma redistribuição de excedente do consumidor.

Trabalhos como o de Felton (1992) e de Seaman (2006) salientam, entretanto, que neste tipo de mercado - o de bens culturais - a elasticidade é de difícil previsão, uma vez que a demanda é sensível a vários fatores, como: características dos consumidores, tipo de bem e serviço e qualidade. Para o caso do teatro, por exemplo, enquanto os trabalhos de Moore (1966) e Gapinski (1984), através do uso de técnicas de estimação com séries de tempo, encontram que sua demanda é inelástica em relação ao preço, Lévy-Garboua e Montemarquette (1996) constatam, a partir do uso de técnicas microeconométricas, que a demanda por teatro é preço-elástica. Dessa forma, os efeitos sobre os consumidores de políticas de regulamentação de preços no mercado de bens culturais é uma questão empírica.

Outro ponto de discussão é que a firma pode, com a aprovação da lei, aumentar os preços dos ingressos, impactando, principalmente, os consumidores que não são estudantes. Assim, a classe de consumidores de não estudantes subsidiaria, pagando preços de ingressos mais caros, os consumidores estudantes. Dessa forma, a lei poderia ser vista como um subsídio cruzado. É importante ressaltar que tal prática, imposta pelo governo, pode causar ineficiências econômicas (FAULHABER (1975) e BAUMOL et.al (1982)).

As leis da meia entrada visam reduzir o preço cobrado de um grupo de consumidores, de modo a incentivar seu consumo de bens e serviços culturais. Leis de meia entrada para determinado grupo forçam empresas a discriminarem preços entre grupos segundo uma regra preestabelecida. Entretanto, os efeitos dessas leis sobre as variações 
dos excedentes precisam ser estudados, pois não está claro quais serão as escolhas das empresas em termos de preços e quantidades vendidas em cada mercado, estando restringidas pela regra de preços imposta pelo governo. Neste estudo, pretende-se dar um primeiro passo na direção de entender os efeitos sobre a consumo do grupo "pretensamente" beneficiado pelas leis em termos da quantidade consumida.

\subsection{Benefícios do consumo de bens e serviços culturais}

A economia da cultura tem o objetivo de estudar os efeitos econômicos que a cultura exerce sobre a sociedade. Bens culturais, segundo Porsse et al. (2007), são bens que têm características de envolver algum tipo de valor cultural e também valor econômico. A cultura também modela as preferências humanas e cria hábitos, ou seja, indivíduos que consomem bens culturais, mudam suas preferências por outros tipos de bens, como, por exemplo, educação.

Segundo Ateca-Amestoy (2007), o consumo de bens culturais amplia o chamado capital cultural. Esse conceito, desenvolvido por Throsby (2000), trata de recursos que representam, possuem ou provém valor cultural, indiferentemente de qualquer valor econômico. Enquanto o valor econômico é reduzido a unidades monetárias, o valor cultural é um conceito coletivo, de crenças e tradições de um grupo. Sociedades que possuam maior estoque de capital cultural são sociedades mais produtivas no que diz respeito às necessidades culturais, como afirma Ateca-Amestoy (2008).

Nesse contexto, a literatura tem buscado relacionar os benefícios do consumo de bens culturais e, por consequência, do estoque de capital cultural sobre o desenvolvimento econômico. Throsby (1999) sugere que a inclusão de capital cultural em uma função de produção fornece resultados semelhantes aos obtidos através do uso do insumo capital humano, na medida em que sociedades com elevados níveis de capital cultural tendem a ter elevados níveis de capital humano. Falck et al. (2011) testam essa hipótese para a Alemanha, explorando um quase experimento de distribuição de casas de ópera de estilo barroco no país, em um período em que ele ainda era descentralizado. 
Segundo os autores, as casas de ópera construídas na Alemanha no período anterior à revolução industrial foram consequências da competição cultural entre reis, duques e príncipes, em uma época em que a prosperidade regional dependia de casamentos estratégicos e alianças de guerra. Os autores encontram resultados de que locais mais próximos a essas casas de ópera tiveram maior desenvolvimento econômico. O mecanismo encontrado para explicar tal resultado é de que cidades com maior diversidade de oferta cultural atraíram mais trabalhadores com alto nível de capital humano, gerando efeito spillover, deslocando positivamente a trajetória de crescimento econômico.

Alguns estudos também atestaram a importância do capital cultural das famílias, medido através dos hábitos de consumo de bens e serviços culturais, para os desempenhos escolares das crianças. Esses estudos, em geral, baseiam-se no argumento de Bourdieu (1973) de que as desigualdades educacionais são reflexos das desigualdades de capital cultural da sociedade. Como exemplo de trabalhos empíricos nessa área, têm-se Tramonte e Willms (2010), que utilizam dados do PISA $^{3}$ do ano 2000 para 28 países, e Gaddis (2013), que por sua vez explora uma base de dados longitudinais de estudantes norte americanos nos anos 90. De maneira geral, esses estudos encontram que um desvio padrão a mais na medida de capital cultural das famílias é relacionado com cerca de 0,15 desvio padrão a mais nos resultados dos exames de aprendizado das crianças.

A relação entre educação e o consumo de cultura já foi evidenciada para dados brasileiros através dos estudos de Diniz e Machado (2011) e Paglioto e Machado (2002). Enquanto Diniz e Machado (2011) avaliam os determinantes do dispêndio de bens e serviços culturais no Brasil, utilizando a POF 2002-2003, Paglioto e Machado (2002) relacionam a probabilidade de um indivíduo brasileiro consumir cultura a determinantes socioeconômicos. Os resultados, de maneira geral, indicam que a renda e a escolaridade são os principais determinantes do consumo de cultura no Brasil. Sendo assim, dados os benefícios que o consumo de cultura gera para o desenvolvimento de uma região, os autores sugerem que as políticas culturais não devem se pautar apenas na ampliação da oferta de bens culturais, mas sim no incentivo da demanda através da redução das desigualdades de educação e de renda.

3 PISA é um programa de avaliação internacional de estudantes na faixa dos 15 anos. 
Nesse sentido, as 27 unidades federativas brasileiras geraram ao longo dos últimos 25 anos alguma forma de legislação que assegura aos estudantes a meia entrada para a participação em eventos culturais. Essa é uma política que se baseia em dois pressupostos fundamentais. O primeiro é fornecer subsídios ao consumo de cultura de um grupo de pessoas, com renda individual média mais baixa. $\mathrm{O}$ segundo é relacionado à interação existente entre capital humano e capital cultural.

A Tabela 1 apresenta as datas de criação e o número das primeiras formas de leis de meia entrada estaduais para todo o país. ${ }^{4}$ Vale ressaltar, no entanto, que pode haver leis da meia entrada municipais anteriores às estaduais. Foi identificado tal fato nas cidades do Rio de Janeiro, onde já havia lei da meia entrada para estudantes desde 1992, Manaus, onde a lei já vigorava desde 1996, e Porto Alegre, que instituiu a lei da meia entrada em 2006. Verifica-se que grande parte dos estados brasileiros promoveu essa política ainda nos anos 90 .

Tabela 1 - Leis estaduais da meia entrada para estudantes

\begin{tabular}{ccc|ccc}
\hline UF & Ano da lei & Número da lei & UF & Ano da lei & Número da lei \\
\hline AC & 1991 & 1004 & PB & 1993 & 5720 \\
AL & 1995 & 5689 & PE & 1993 & 10859 \\
AM & 2006 & 3076 & PI & 1994 & 4,673 \\
AP & 1993 & 102 & PR & 1995 & 11182 \\
BA & 1990 & 5894 & RJ & 1996 & 2519 \\
CE & 1994 & 12302 & RN & 1993 & 6503 \\
DF & 2001 & 2768 & RO & 1994 & 552 \\
ES & 1994 & 4955 & RR & 1995 & 95 \\
GO & 1994 & 12355 & RS & 2008 & 13104 \\
MA & 2002 & 7805 & SC & 2003 & 12570 \\
MG & 1993 & 11052 & SE & 1994 & 3491 \\
MS & 1992 & 1352 & SP & 1992 & 7844 \\
MT & 1991 & 5729 & TO & 1997 & 934 \\
PA & 1993 & 5764 & & & \\
\hline
\end{tabular}

Fonte: Assembleias Legislativas Regionais.

${ }^{4}$ Em dezembro de 2013 foi sancionada uma lei federal da meia entrada (Lei $N^{\circ}$ 12.933). 


\section{Metodologia}

\subsection{Estratégia empírica}

As leis de meia entrada aos estudantes alteram os preços relativos dos bens culturais e, dessa forma, tendem a influenciar o consumo. Os bens e serviços culturais considerados nesse trabalho são aqueles elegíveis a meia entrada. São eles os seguintes: ópera, dança clássica, museu, exposição, teatro, cinema, show e circo. Para tanto se utilizaram as informações amostrais da Pesquisa de Orçamento Familiar (POF), cujos entrevistados respondem a questionários a respeito do seu perfil de consumo sobre diversos bens e serviços, inclusive os culturais.

A estratégia empírica utilizada nesse trabalho para mensurar o efeito das leis de meia entrada sobre o consumo de cultura dos estudantes nas regiões metropolitanas visa explorar os diferentes anos de criação da meia entrada entre os estados e, por consequência, entre as regiões metropolitanas brasileiras. São analisados os efeitos em grupos de regiões metropolitanas, construídos em função da data de criação das leis. Dadas essas características, o presente trabalho adota duas estratégias empíricas para identificação de causalidade. A primeira delas, o estimador de Diferenças-em-Diferenças (DD), utiliza na amostra apenas as regiões metropolitanas que tiveram a criação de lei de meia entrada em algum momento no período de toda a análise. Assim, a implementação do DD, nesse estudo, baseia-se na estimação da seguinte equação:

$$
\begin{gathered}
y_{i j t}=\alpha_{j}+\phi_{t}+\delta_{0} \text { Estudante }_{i j t}+\delta_{1} \text { PósLei }_{t} \cdot \text { Estudante }_{i j t}+\gamma^{\prime} \text { Socioec }_{i j t}+ \\
\lambda^{\prime} \text { Educ }_{i j t}+\eta^{\prime} \text { Dem }_{i j t}+u_{i j t}
\end{gathered}
$$

onde $y_{i j t}$ pode assumir duas formas. A primeira é uma variável binária que assume valor 1 para os indivíduos que consumiram algum bem ou serviço cultural privado no mês de referência. A segunda forma é o dispêndio em unidades monetárias com bens e serviços culturais no mês de referência. A opção de utilizar duas variáveis respostas diferentes decorre do fato de que o consumo é uma variável censurada. Esse problema se torna ainda maior para o consumo de bens e serviços culturais, uma vez que apenas uma pequena parte da população brasileira é consumidora desses bens. 
O subscrito $i$ refere-se ao indivíduo, o $j$ às regiões metropolitanas analisadas e o $t$ ao tempo.

A variável Estudante é uma dummy que possui valor 1 para o grupo tratado, ou seja, o grupo dos estudantes. A variável Póslei é uma dummy para o período posterior à implementação da lei. O termo $\alpha_{j}$ capta o efeito fixo de região metropolitana com o objetivo de controlar características particulares e constantes ao longo do tempo de cada região. Já o termo $\phi_{t}$ capta o efeito fixo de tempo, ${ }^{5}$ visando controlar tendência, flutuações macroeconômicas e outras políticas culturais comuns. São acrescentados a Equação (1) ainda grupos de covariadas para controlar heterogeneidades dos indivíduos. São eles os vetores Sociec, com características socioeconômicas, Educ, com características educacionais e, por fim, Dem, com características sociodemográficas.

As características socioeconômicas utilizadas como controles neste trabalho são a renda per capita da unidade de consumo (UC) e o hábito de consumo cultural nas UC dos indivíduos. Esta última é uma variável binária que identifica se houve consumo de bens e serviços complementares aos bens culturais no período de referência, assim como é feito no trabalho de Diniz e Machado (2012). Os bens e serviços complementares considerados são os seguintes: instrumentos e acessórios musicais, bens de cultura visual, artigos de leitura e aparelhos de vídeo e DVD. Como características educacionais dos indivíduos, utilizam-se os anos de estudo. Como características sociodemográficas utilizam-se a idade dos indivíduos e uma variável binária de gênero.

Para o caso em que a variável dependente corresponda à variável binária, se o indivíduo consumiu ou não bens e serviços culturais no mês de referência, empregam-se as metodologias de estimação Probit e Logit na Equação (1). ${ }^{6}$ A aplicação desses métodos é usualmente motivada pela hipótese de que a variável resposta é determinada por uma variável latente. A diferença básica entre os métodos está na distribuição da variável latente. Enquanto o Probit assume uma distribuição normal, o Logit assume uma distribuição logística.

5 Como o período de coleta da POF é de um ano, a unidade de tempo é a semana de referência da pesquisa para cada UC. Sendo assim, o efeito fixo de tempo controla tanto a semana de referência quanto o ano da pesquisa.

6 Puhani (2012) demonstra que os coeficientes dos modelos DD são válidos em estimações de modelos não lineares como Probit, Logit e Tobit. 
Os resultados entre as duas estimações, no entanto, tendem a ser semelhantes para casos não extremos. Já quando a variável resposta for o gasto com bens e serviços culturais, a metodologia empregada é o Tobit. Esse método de estimação pressupõe um gasto latente para os indivíduos que não consumiram cultura no mês de referência. Em todas as especificações, os erros padrões são robustos e clusterizados ao nível da região metropolitana, permitindo correlação dentro da região metropolitana para um período ou entre os períodos.

O principal parâmetro de interesse da Equação (1) a ser estimado é $\delta_{1}$. Ele captura o efeito causal das leis de meia entrada sobre o consumo de bens e serviços culturais dos estudantes sob a hipótese de que as tendências de consumo, condicionais aos controles, seriam as mesmas entre estudantes e não estudantes se as leis não tivessem sido criadas. Em outras palavras, o parâmetro $\delta_{1}$ estimado fornecerá uma interpretação causal se não houverem variáveis omitidas no modelo que desviem as tendências de consumo dos grupos tratado e não tratado. Existem fatores não relacionados com a meia entrada, no entanto, que podem afetar a relação entre o consumo de bens e serviços culturais entre os grupos tratado e não tratado ao longo do tempo. Um exemplo é a disseminação do consumo de conteúdo cultural através da internet. Se os estudantes aderiram mais a essa forma de conteúdo cultural, a trajetória entre os grupos poderá mudar no tempo e, assim, o parâmetro de interesse estimado pela Equação (1) não fornecerá o efeito do tratamento.

Dessa forma, adota-se uma segunda estratégia empírica neste traba1ho. Essa estratégia visa utilizar uma diferente análise DD, incorporando mais um grupo de controle para a realização de uma terceira diferença (diferenças triplas (DDD)). No presente estudo, formarão o grupo controle adicional as regiões metropolitanas que não tiveram a criação de lei de meia entrada no período. Essa estratégia, baseada no modelo (1), é definida pela seguinte equação:

$$
\begin{gathered}
y_{i j t}=\alpha_{j}+\phi_{t}+\delta_{0} \text { Estudante }_{i j t}+\delta_{1} \text { RM Tratada }_{j} \cdot \text { Estudante }_{i j t}+\delta_{2} \text { PósLei }_{t} \cdot \\
\text { RM tratada }_{j}+\delta_{3} \text { PósLei }_{t} \cdot \text { Estudante }_{i j t}+\delta_{4} \text { PósLei }_{t} \cdot \text { RM tratada }_{j} . \\
\text { Estudante }_{i j t}+\gamma^{\prime} \text { Socioec }_{i j t}+\lambda^{\prime} \text { Educ }_{i j t}+\eta^{\prime} \text { Dem }_{i j t}+u_{i j t}
\end{gathered}
$$

onde RM tratada é uma dummy que assume valor 1 para os indivíduos entrevistados nas regiões metropolitanas que tiveram a imple- 
mentação de meia entrada no período de análise. Sob a hipótese de que os diferenciais de tendências entre estudantes e não estudantes, na ausência da criação da lei, são similares entre as regiões metropolitanas, o coeficiente da tripla interação $\left(\delta_{4}\right)$ fornece a relação causal do efeito tratamento. Assim como no caso da Equação (1), a Equação (2) também é estimada por Probit, Logit e Tobit, dependendo se a variável resposta for binária ou contínua.

A validade de modelos Tobit, no entanto, é sensível a hipóteses básicas. O estimador de Tobit será inconsistente se os erros da regressão forem heterocedásticos ou não normais. Para controlar uma possível má especificação, no que diz respeito à heterocedasticidade, é comum a utilização de matriz de variância e covariância robusta para a estimação. No que diz respeito à hipótese de normalidade, contudo, variáveis de gastos monetários são geralmente não normais. A Tabela (2) apresenta as características das distribuições dos gastos com bens e serviços culturais e de sua forma em logaritmo natural. Diferentemente do que ocorre com a distribuição dos gastos com bens e serviços culturais, o logaritmo natural dessa variável é aproximadamente simetricamente distribuído e com excesso de curtose insignificante. Dessa forma, a variável dependente das estimações do modelo Tobit é alterada para o logaritmo natural dos gastos com bens e serviços culturais.

Tabela 2 - Estatísticas descritivas dos gastos com bens e serviços culturais

\begin{tabular}{lcccc}
\hline & Média & Desvio Padrão & Assimetria & Curtose \\
\hline Gastos com bens e serviços culturais & 3,26 & 21,07 & 23,37 & 1162,45 \\
Ln(gastos com bens e serviços culturais) & 3,23 & 0,96 & 0,25 & 3,1 \\
\hline
\end{tabular}

Fonte: Elaboração própria baseada nos dados da POF/IBGE.

Embora os coeficientes de interesse estimados por modelos Probit e Logit forneçam o sinal do efeito das leis de meia entrada sobre o consumo de bens e serviços culturais, eles não possuem interpretações de efeito tratamento da lei. Para esses modelos, o efeito tratamento, como observado por Puhani (2012), é dado pelo efeito incremental do coeficiente do termo de interação da regressão. Já o coeficiente de interesse estimado por Tobit é o efeito tratamento médio estimado da lei sobre os gastos com bens e serviços culturais latentes. Dessa forma, além dos coeficientes estimados e de seus testes de significância, para os modelos de resposta binária, calcula- 
se o efeito tratamento por observação, o que permite análises que verifiquem possíveis efeitos heterogêneos da criação das leis de meia entrada para estudantes.

\subsection{Amostra}

A amostra baseia-se nas quatro Pesquisas de Orçamentos Familiares (POF) divulgadas pelo Instituto Brasileiro de Geografia e Estatística (IBGE). A primeira foi realizada entre 1987 e 1988, a segunda entre 1995 e 1996, a terceira entre 2002 e 2003 e a quarta realizada entre 2008 e 2009. A POF é uma pesquisa amostral, sem representatividade municipal, mas com representatividade estadual, por região metropolitana e capitais. A pesquisa destina-se a questionar o perfil dos gastos monetários dos entrevistados somente de pessoas acima dos 10 anos de idade, no mês de referência, anterior a realização da entrevista. Além disso, há informações sobre o perfil socioeconômico dos entrevistados.

São utilizados quatro questionários da pesquisa: o de características dos domicílios e dos moradores, o de aquisição coletiva da UC, o de aquisição individual e o de trabalho e rendimento individual, considerando os dados dos entrevistados de todas as regiões metropolitanas do Brasil. ${ }^{7}$ Especificamente, o questionário de aquisição individual disponibiliza informações dos bens elegíveis à meia entrada para cada membro da UC com mais de 10 anos, enquanto que o questionário de aquisição coletiva da UC disponibiliza informações de aquisições de bens e serviços complementares, utilizados como variáveis de controles.

A decisão de se utilizar apenas as informações das regiões metropolitanas é fundamentada em dois argumentos. O primeiro, como afirma Paglioto e Machado (2002), é que a localização é um determinante da oferta de cultura, o que resulta em maior vantagem aos grandes centros urbanos. O segundo argumento reside no fato de que as POF de 1987/88 e 1995/96 foram realizadas apenas nas regiões metropolitanas brasileiras. ${ }^{8}$

7 Cada questionário pode ter mais de uma base de dados disponibilizada em microdados pelo IBGE, quantidade que pode variar dependendo do ano da pesquisa.

8 As regiões metropolitanas brasileiras como determinado pelas POF são Salvador, Fortaleza, Goiânia, Belo Horizonte, Belém, Recife, São Paulo, Rio de Janeiro, Brasília, Curitiba e Porto Alegre. 
Como mencionado anteriormente, os bens e serviços culturais considerados neste trabalho são ópera, dança clássica, museu, exposição, teatro, cinema, show e circo. A Tabela 3 fornece as estatísticas descritivas da amostra, empilhando as quatro pesquisas, para consumidores e não consumidores de cultura. Os dados monetários foram deflacionados pelo IPCA.

Tabela 3 - Estatísticas descritivas

\begin{tabular}{|c|c|c|c|c|c|}
\hline \multirow{2}{*}{ Características } & \multirow{2}{*}{ Variável } & \multicolumn{2}{|c|}{ Consumiu Cultura } & \multicolumn{2}{|c|}{ Não Consumiu Cultura } \\
\hline & & Valor & Erro-Padrão & Valor & Erro-Padrão \\
\hline \multirow{2}{*}{ Sociodemográficas } & Parcela de homens & 0,59 & 0,49 & 0,46 & 0,5 \\
\hline & Média de idade (em anos) & 27,01 & 11,12 & 31,83 & 14,3 \\
\hline \multirow{2}{*}{ Educacionais } & Anos médios de estudo & 10,26 & 3,78 & 6,73 & 4,12 \\
\hline & Parcela de estudante & 0,41 & 0,49 & 0,26 & 0,44 \\
\hline \multirow{4}{*}{ Socioeconômicas } & $\begin{array}{l}\text { Renda per capita média da Unidade } \\
\text { de Consumo (em R\$) }\end{array}$ & 3177,59 & 5082,08 & 1564,26 & 2571,7 \\
\hline & $\begin{array}{l}\text { Gasto médio com cultura (em } R \$ \text { ) no } \\
\text { mês de referência }\end{array}$ & 42,17 & 64,06 & - & - \\
\hline & $\begin{array}{l}\text { Porcentagem da renda gasta com } \\
\text { bens e serviços culturais }\end{array}$ & $10 \%$ & $23 \%$ & - & - \\
\hline & $\begin{array}{l}\text { Gasto com bens complementares no } \\
\text { mês de referência }\end{array}$ & 145,92 & 685,23 & 64,78 & 438,82 \\
\hline Observações & 9791 & 116838 & & & \\
\hline
\end{tabular}

Fonte: POF 1987/88, 1995/96, 2002/03 e 2008/09.

As estatísticas evidenciam que, em média, o consumidor de cultura é mais jovem, com maior escolaridade e com renda per capita domiciliar da (UC) superior. Outra relação importante diz respeitos aos estudantes. Verifica-se uma participação maior de estudantes entre os indivíduos que consumiram algum bem ou serviço cultural no mês de referência.

\section{Resultados}

A estratégia empírica deste trabalho baseia-se na mensuração das diferenças entre estudantes e não estudantes no que diz respeito a participação e gasto no consumo de bens e serviços culturais. Para tanto, além de uma análise para toda a amostra, dividem-se as regiões metropolitanas em dois grupos. $\mathrm{O}$ primeiro corresponde às regiões metropolitanas que tiveram a implementação das leis de meia 
entrada entre as POF 1987/88 e 1995/96. São elas as seguintes: Salvador, Fortaleza, Goiânia, Belo Horizonte, Belém, Recife e São Paulo. Nesse grupo, inclui-se também a cidade do Rio de Janeiro, por já ter uma lei municipal para a meia entrada de estudantes em 1992, anterior à lei estadual. O segundo grupo diz respeito às regióes metropolitanas que tiveram a implementação das leis entre as POF 1995/96 e 2002/03. Nesse grupo, as regiões metropolitanas presentes são as seguintes: Brasília, Curitiba e Rio de Janeiro, excluindo a capital. A região metropolitana de Porto Alegre foi a única a ter data de criação da lei posterior a 2003. A capital do estado do Rio Grande do Sul teve a criação da lei em 2006, enquanto a lei para o estado surgiu apenas em 2008. Sendo assim, Porto Alegre é considerada apenas quando a análise for para todas as regiões metropolitanas conjuntamente.

A Figura 1 apresenta os gráficos das evoluções das proporções de consumidores de cultura ao longo do tempo para as regiões metropolitanas que tiveram a criação da meia entrada entre 1987 e 1995 e entre 1995 e 2002. Sem condicionar a outros fatores, tanto nas regiões metropolitanas que tiveram a implementação da meia entrada entre 1987 e 1995, quanto naquelas em que a meia entrada surgiu entre 1995 e 2002, percebe-se que a diferença entre a proporção de estudantes e não estudantes consumidores de bens e serviços culturais se reduz de 1987 para 1995, aumentando posteriormente. Para as regiões metropolitanas que criaram a meia entrada no segundo período de análise, percebe-se um comportamento mais errático da diferença entre os grupos.
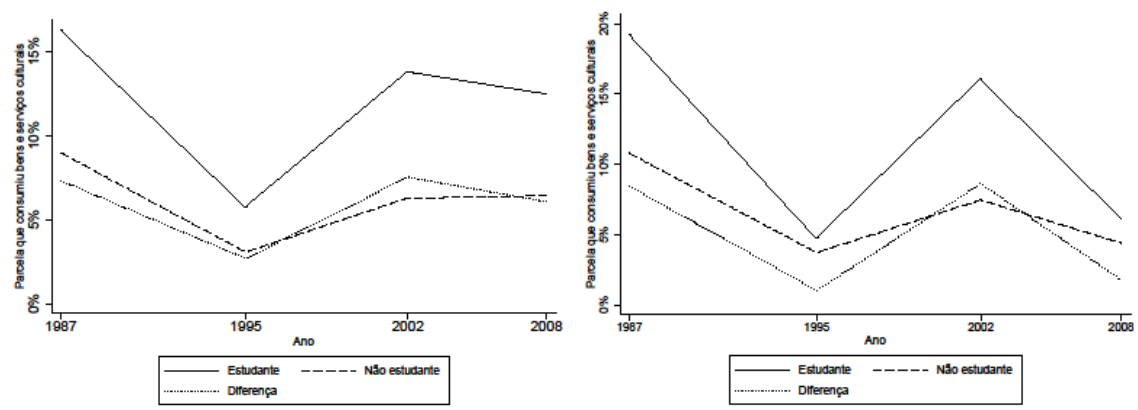

Figura 1- Parcela de consumidores de bens e serviços culturais nas regiões metropolitanas que tiveram a criação de leis de meia entrada entre 1987 e 1995 (à esquerda) e entre 1995 à 2002 (à direita).

Fonte: Elaboração própria. 


\subsection{Resultados das estimações DD}

A Tabela 4 apresenta os resultados das estimações DD através dos métodos Probit, Logit e Tobit para as regiões metropolitanas, agrupadas, que tiveram leis de meia entrada implementada entre 1988 e 1995. Além dos diferentes métodos, também testaram-se efeitos diferentes de curto e longo prazo. Para o longo prazo, utilizaram-se todas as informações até a POF2008/09, enquanto que para o curto prazo a amostra é restrita em apenas um período posterior a criação da lei.

Conforme discutido na seção 3 , o coeficiente de interesse é aquele associado à variável da Equação (1). O coeficiente estimado é significativo em todas as formulações, com nível de significância de pelo menos $10 \%$. Para os casos em que a regressão é realizada com toda a amostra possível, o coeficiente é significativo a $1 \%$, com exceção do modelo Logit. Sob a hipótese de que a diferença entre as proporções de consumidores e não consumidores de cultura (para o caso das estimações Probit e Logit) manter-se-iam as mesmas para estudantes e não estudantes sem a intervenção, pode-se afirmar que a meia entrada teve efeito em aumentar a probabilidade dos estudantes consumirem bens e serviços culturais. Analogamente, a estimação Tobit identifica que a meia entrada teve impacto em aumentar seus gastos médios com cultura. Embora os coeficientes do modelo Probit e Logit não forneçam o tamanho do efeito tratamento (implementação da meia entrada para estudantes), conforme constatado por Puhani (2012), os coeficientes fornecem o sinal e a significância do efeito. ${ }^{9}$ Essas estimativas, no entanto, não são válidas se o comportamento sobre o consumo de cultura entre os estudantes e não estudantes mudarem ao longo do tempo.

Para o caso do estimador do modelo Tobit, entretanto, o coeficiente fornece o efeito tratamento médio da política. Para a amostra intei$\mathrm{ra}$ o coeficiente indica que a política teve resultado em aumentar os gastos dos estudantes com bens e serviços culturais em $96 \%$, em média, enquanto que para a amostra reduzida o resultado foi cerca de $89 \% .{ }^{10}$ Esse resultado, apesar de muito significativo em termos de impacto, deve-se ao fato de os gastos médios com cultura serem pequenos, $\mathrm{R} \$ 3,26$ para o período de análise. Ainda, é necessária a

9 Os efeitos do tratamento serão calculados apenas para as estimações DDD.

${ }^{10}$ Esses resultados, no entanto, referem-se a variável latente gastos com bens e serviços culturais. 
hipótese de que a relação entre as tendências dos gastos com cultura manter-se-iam as mesmas ao longo do tempo, sem a aplicação das leis de meia entrada.

Tabela 4 - Coeficientes das estimações DD para as regiões metropolitanas que tiveram a criação da meia entrada entre 1988 e 1995

\begin{tabular}{|c|c|c|c|c|c|c|}
\hline \multicolumn{5}{|c|}{ Variável dependente: 1 se o indivíduo consumiu bens culturais e 0 caso contrário } & \multicolumn{2}{|c|}{$\begin{array}{l}\text { Variável dependente: } \\
\text { In(gastos com bens e } \\
\text { serviços culturais) }\end{array}$} \\
\hline & $\begin{array}{l}\text { Probit } \\
\text { (1) }\end{array}$ & $\begin{array}{l}\text { Probit } \\
\text { (2) }\end{array}$ & $\begin{array}{l}\text { Logit } \\
\text { (3) }\end{array}$ & $\begin{array}{l}\text { Logit } \\
\text { (4) }\end{array}$ & $\begin{array}{l}\text { Tobit } \\
(5)\end{array}$ & $\begin{array}{l}\text { Tobit } \\
(6)\end{array}$ \\
\hline Estudante*Pós lei & $\begin{array}{l}0,162^{\star \star *} \\
(0,0606)\end{array}$ & $\begin{array}{c}0,146^{*} \\
(0,0758)\end{array}$ & $\begin{array}{l}0,286^{* *} \\
(0,114)\end{array}$ & $\begin{array}{l}0,286^{* *} \\
(0,146)\end{array}$ & $\begin{array}{l}0,964^{\star * *} \\
(0,334)\end{array}$ & $\begin{array}{l}0,886^{\star *} \\
(0,401)\end{array}$ \\
\hline Estudante & $\begin{array}{c}0,104^{*} \\
(0,0626)\end{array}$ & $\begin{array}{c}0,0566 \\
(0,0667)\end{array}$ & $\begin{array}{l}0,205^{\star} \\
(0,114)\end{array}$ & $\begin{array}{l}0,0853 \\
(0,119)\end{array}$ & $\begin{array}{c}0,498 \\
(0,334)\end{array}$ & $\begin{array}{c}0,257 \\
(0,354)\end{array}$ \\
\hline Homem & $\begin{array}{l}0,295^{\star * \star} \\
(0,0311)\end{array}$ & $\begin{array}{l}0,410^{\star * *} \\
(0,0271)\end{array}$ & $\begin{array}{l}0,580^{\star \star \star} \\
(0,0664)\end{array}$ & $\begin{array}{l}0,818^{\star * \star} \\
(0,0562)\end{array}$ & $\begin{array}{c}1,630^{\star * \star} \\
(0,162)\end{array}$ & $\begin{array}{c}2,211^{\star \star \star} \\
(0,123)\end{array}$ \\
\hline Idade & $\begin{array}{l}-0,0205^{\star \star \star} \\
(0,00143)\end{array}$ & $\begin{array}{l}-0,0237^{\star \star \star} \\
(0,00168)\end{array}$ & $\begin{array}{l}-0,0448^{\star \star *} \\
(0,00314)\end{array}$ & $\begin{array}{l}-0,0527^{\star \star \star} \\
(0,00395)\end{array}$ & $\begin{array}{l}-0,110^{\star \star \star} \\
(0,00677)\end{array}$ & $\begin{array}{l}-0,125^{\star \star \star} \\
(0,00796)\end{array}$ \\
\hline Anos de estudo & $\begin{array}{l}0,116^{\star \star *} \\
(0,00450)\end{array}$ & $\begin{array}{l}0,112^{\star \star \star} \\
(0,00480)\end{array}$ & $\begin{array}{l}0,234^{\star * *} \\
(0,00952)\end{array}$ & $\begin{array}{l}0,225^{* * *} \\
(0,0106)\end{array}$ & $\begin{array}{l}0,660^{* * *} \\
(0,0223)\end{array}$ & $\begin{array}{l}0,628^{* * *} \\
(0,0229)\end{array}$ \\
\hline Hábito cultural & $\begin{array}{l}0,412^{\star * *} \\
(0,0128)\end{array}$ & $\begin{array}{l}0,460^{* * *} \\
(0,0202)\end{array}$ & $\begin{array}{l}0,765^{* * *} \\
(0,0247)\end{array}$ & $\begin{array}{l}0,848^{* * *} \\
(0,0386)\end{array}$ & $\begin{array}{l}2,263^{\star * *} \\
(0,0509)\end{array}$ & $\begin{array}{l}2,468^{* * *} \\
(0,0730)\end{array}$ \\
\hline $\begin{array}{c}\text { Renda per capita } \\
\text { da UC }\end{array}$ & $\begin{array}{l}0,0000282^{\star \star *} \\
(0,00000341)\end{array}$ & $\begin{array}{l}0,0000194^{* * *} \\
(0,00000330)\end{array}$ & $\begin{array}{l}0,0000490^{* * *} \\
(0,00000584)\end{array}$ & $\begin{array}{l}0,0000323^{* * *} \\
(0,00000578)\end{array}$ & $\begin{array}{l}0,000144^{\star * *} \\
(0,0000256)\end{array}$ & $\begin{array}{l}0,000101^{* * *} \\
(0,0000225)\end{array}$ \\
\hline $\begin{array}{l}\text { Efeito fixo de região } \\
\text { metropolitana }\end{array}$ & Sim & Sim & Sim & $\operatorname{Sim}$ & Sim & $\operatorname{Sim}$ \\
\hline Efeito fixo de tempo & $\operatorname{Sim}$ & Sim & Sim & Sim & Sim & Sim \\
\hline Constante & $\begin{array}{c}-2,215^{\star \star \star} \\
(0,147)\end{array}$ & $\begin{array}{l}-2,082^{\star \star *} \\
(0,0928)\end{array}$ & $\begin{array}{c}-3,972^{\star \star *} \\
(0,308)\end{array}$ & $\begin{array}{c}-3,671^{\star * *} \\
(0,183)\end{array}$ & $\begin{array}{c}-12,92^{\star \star *} \\
(0,871) \\
\end{array}$ & $\begin{array}{c}-12,04^{\star \star *} \\
(0,547) \\
\end{array}$ \\
\hline Observações & 91210 & 62870 & 91210 & 62870 & 91230 & 62870 \\
\hline POF utilizadas & $\begin{array}{c}1987 / 88 \\
1995 / 96 \\
2002 / 03 \text { e } \\
2008 / 09\end{array}$ & $\begin{array}{c}1987 / 88 \text { e } \\
1995 / 96\end{array}$ & $\begin{array}{c}1987 / 88 \\
1995 / 96 \\
2002 / 03 \text { e } \\
2008 / 09\end{array}$ & $\begin{array}{c}1987 / 88 \text { e } \\
1995 / 96\end{array}$ & $\begin{array}{c}1987 / 88 \\
1995 / 96 \\
2002 / 03 \text { e } \\
2008 / 09\end{array}$ & $\begin{array}{c}1987 / 88 \text { e } \\
1995 / 96\end{array}$ \\
\hline
\end{tabular}

Nota: Modelos estimados conforme a Equação (1).

Erros padrões robustos clusterizados a nível das regiões metropolitanas em parênteses.

Pós Lei é uma dummy que assume valor 1 para o período maior ou igual a 1995/96.

As regiões metropolitanas que pertencem a esse grupo de estimação são: Salvador, Fortaleza, Goiânia, Belo Horizonte, Belém, Recife, Rio de Janeiro capital e São Paulo.

* Estatisticamente significante a $10 \%$.

** Estatisticamente significante a 5\%.

*** Estatisticamente significante a $1 \%$. 
A Tabela 5 apresenta os coeficientes estimados para as regiões metropolitanas que tiveram a criação de leis de meia entrada entre os anos de 1996 e 2003. Assim como no caso anterior, são feitas especificações diferentes para capturar possíveis efeitos de curto e longo prazo. Diferentemente das estimações para as regiões metropolitanas que tiveram a criação da lei entre 1988 e 1995, o coeficiente de interesse não é significativo em nenhuma das estimações.

Tabela 5 - Coeficientes das estimações DD para as regiões metropolitanas que tiveram a criação da meia entrada entre 1996 e 2003

\begin{tabular}{|c|c|c|c|c|c|c|}
\hline & \multicolumn{4}{|c|}{$\begin{array}{l}\text { Variável dependente: } 1 \text { se } 0 \text { indivíduo consumiu bens } \\
\text { culturais e } 0 \text { caso contrário }\end{array}$} & \multicolumn{2}{|c|}{$\begin{array}{l}\text { Variável dependente: } \\
\text { In(gastos com bens e } \\
\text { serviços culturais }\end{array}$} \\
\hline & $\begin{array}{l}\text { Probit } \\
(1)\end{array}$ & $\begin{array}{l}\text { Probit } \\
(2)\end{array}$ & $\begin{array}{l}\text { Logit } \\
(3)\end{array}$ & $\begin{array}{l}\text { Logit } \\
(4)\end{array}$ & $\begin{array}{l}\text { Tobit } \\
(5)\end{array}$ & $\begin{array}{c}\text { Tobit } \\
(6)\end{array}$ \\
\hline $\begin{array}{l}\text { Estudante*Pós } \\
\text { lei }\end{array}$ & 0,00639 & 0,0368 & $-0,0104$ & 0,0467 & 0,101 & 0,268 \\
\hline & $(0,133)$ & $(0,0758)$ & $(0,264)$ & $(0,153)$ & $(0,736)$ & $(0,246)$ \\
\hline Estudante & $\begin{array}{c}0,114 \\
(0,0842)\end{array}$ & $\begin{array}{c}0,104 \\
(0,0766)\end{array}$ & $\begin{array}{c}0,232 \\
(0,156)\end{array}$ & $\begin{array}{c}0,204 \\
(0,138)\end{array}$ & $\begin{array}{c}0,573 \\
(0,466)\end{array}$ & $\begin{array}{l}0,525^{\star * \star} \\
(0,0419)\end{array}$ \\
\hline Homem & $0,310^{* * *}$ & $\begin{array}{l}0,337^{* \star *} \\
(0,0275)\end{array}$ & $\begin{array}{l}0,614^{* \star *} \\
(0,0656)\end{array}$ & $\begin{array}{l}0,664^{\star \star \star} \\
(0,0522)\end{array}$ & $\begin{array}{l}1,749^{* \star *} \\
(0,137)\end{array}$ & $\begin{array}{l}1,880^{* \star *} \\
(0,0124)\end{array}$ \\
\hline Idade & $\begin{array}{l}-0,0183^{\star \star *} \\
(0,00285)\end{array}$ & $\begin{array}{l}-0,0190^{\star \star *} \\
(0,00319)\end{array}$ & $\begin{array}{l}-0,0390^{\star \star *} \\
(0,00633)\end{array}$ & $\begin{array}{l}-0,0404^{\star \star *} \\
(0,00734)\end{array}$ & $\begin{array}{c}-0,0990^{\star * *} \\
(0,0171)\end{array}$ & $\begin{array}{l}-0,101^{\star * *} \\
(0,000528)\end{array}$ \\
\hline Anos de estudo & $\begin{array}{l}0,108^{\star * *} \\
(0,00531)\end{array}$ & $\begin{array}{l}0,105^{\star * *} \\
(0,00467)\end{array}$ & $\begin{array}{l}0,214^{* * *} \\
(0,0105)\end{array}$ & $\begin{array}{l}0,206^{* * *} \\
(0,00920)\end{array}$ & $\begin{array}{l}0,628^{* * *} \\
(0,0388)\end{array}$ & $\begin{array}{l}0,606^{* * *} \\
(0,00178)\end{array}$ \\
\hline Hábito cultural & $\begin{array}{l}0,457^{\star \star *} \\
(0,0548)\end{array}$ & $\begin{array}{l}0,461^{* * *} \\
(0,0511)\end{array}$ & $\begin{array}{c}0,842^{* \star *} \\
(0,105)\end{array}$ & $\begin{array}{l}0,842^{* * *} \\
(0,0989)\end{array}$ & $\begin{array}{c}2,543^{* * *} \\
(0,292)\end{array}$ & $\begin{array}{l}2,530^{* * *} \\
(0,0300)\end{array}$ \\
\hline $\begin{array}{c}\text { Renda per capita } \\
\text { da UC }\end{array}$ & $0,0000289^{* * *}$ & $0,0000279^{* * *}$ & $0,0000541^{* * *}$ & $0,0000527^{\star \star \star}$ & $0,000172^{\star \star *}$ & $0,000167^{\star \star *}$ \\
\hline & $(0,00000900)$ & $(0,00000989)$ & $(0,0000149)$ & $(0,0000167)$ & $(0,0000468)$ & $(0,00000124)$ \\
\hline $\begin{array}{l}\text { Efeito fixo } \\
\text { de região } \\
\text { metropolitana }\end{array}$ & Sim & $\operatorname{Sim}$ & Sim & Sim & Sim & Sim \\
\hline $\begin{array}{l}\text { Efeito fixo de } \\
\quad \text { tempo }\end{array}$ & Sim & Sim & $\mathrm{Si}$ & Sim & Sim & Sim \\
\hline Constante & $\begin{array}{c}-2,428^{\star \star \star} \\
(0,270)\end{array}$ & $\begin{array}{c}-2,332^{* * *} \\
(0,631)\end{array}$ & $\begin{array}{c}-4,438^{\star \star \star} \\
(0,532)\end{array}$ & $\begin{array}{c}-4,105^{\star \star \star} \\
(1,238)\end{array}$ & $\begin{array}{c}-14,52^{\star * *} \\
(1,183)\end{array}$ & $\begin{array}{c}-34,16^{\star \star *} \\
(0,0112)\end{array}$ \\
\hline Observações & 26049 & 22250 & 26049 & 22250 & 26447 & 22377 \\
\hline POF utilizadas & $\begin{array}{c}1987 / 88 \\
1995 / 96 \\
2002 / 03 \text { e } \\
2008 / 09\end{array}$ & $\begin{array}{c}1987 / 88 \\
1995 / 96 \text { e } \\
2002 / 03\end{array}$ & $\begin{array}{c}1987 / 88, \\
1995 / 96, \\
2002 / 03 \text { e } \\
2008 / 09\end{array}$ & $\begin{array}{c}\text { 1987/88, } \\
1995 / 96 \text { e } \\
\text { 2002/03 }\end{array}$ & $\begin{array}{c}1987 / 88 \\
1995 / 96 \\
2002 / 03 \text { e } \\
2008 / 09\end{array}$ & $\begin{array}{c}\text { 1987/88, } \\
1995 / 96 \text { e } \\
2002 / 03\end{array}$ \\
\hline
\end{tabular}

Nota: Modelos estimados conforme a Equação (1).

Erros padrões robustos clusterizados a nível das regiões metropolitanas em parênteses.

Pós Lei é uma dummy que assume valor 1 para o período maior ou igual a 1995/96.

As regiões metropolitanas que pertencem a esse grupo de estimação são: Brasília, Curitiba e Rio de Janeiro, excluindo a capital.

* Estatisticamente significante a $10 \%$.

** Estatisticamente significante a 5\%.

*** Estatisticamente significante a $1 \%$. 
Agregando todas as regiões metropolitanas e identificando o período pós lei para cada uma delas, é possível construir uma estimativa agregada. A Tabela 6 apresenta os coeficientes estimados. Sob a hipótese de que as tendências de consumo de cultura entre estudantes e não estudantes manter-se-iam as mesmas na ausência da lei, os resultados sugerem que, em média, a meia entrada foi eficaz tanto em aumentar a probabilidade dos indivíduos das regiões metropolitanas consumirem bens e serviços culturais, como em aumentar seus gastos com esses bens. Esses resultados, no entanto, são suscetíveis a hipótese levantada de que não existem variáveis omitidas no modelo que alterem a relação de consumo de bens e serviços culturais entre estudantes e não estudantes no tempo.

Tabela 6 - Coeficientes das estimações DD para todas as regiões metropolitanas

\begin{tabular}{|c|c|c|c|}
\hline & \multicolumn{2}{|c|}{$\begin{array}{l}\text { Variável dependente: } 1 \text { se o indivíduo consumiu } \\
\text { bens culturais e } 0 \text { caso contrário }\end{array}$} & \multirow{2}{*}{$\begin{array}{c}\text { Variável dependente: In(gastos } \\
\text { com bens e serviços culturais) } \\
\text { Tobit } \\
\text { (3) }\end{array}$} \\
\hline & $\begin{array}{l}\text { Probit } \\
\text { (1) }\end{array}$ & $\begin{array}{l}\text { Logit } \\
\text { (2) }\end{array}$ & \\
\hline \multirow[t]{2}{*}{ Estudante*Pós lei } & $0,117^{\star \star}$ & $0,207^{\star \star}$ & $0,720^{\star \star \star}$ \\
\hline & $(0,0491)$ & $(0,0916)$ & $(0,272)$ \\
\hline \multirow{2}{*}{ Estudante } & $0,123^{* * *}$ & $0,236^{* * *}$ & $0,616^{\star * \star}$ \\
\hline & $(0,0423)$ & $(0,0756)$ & $\begin{array}{c}(0,229) \\
1,618^{* * *}\end{array}$ \\
\hline Homem & $(0,0214)$ & $(0,0449)$ & $\begin{array}{l}, 010 \\
(0,112)\end{array}$ \\
\hline \multirow[t]{2}{*}{ Idade } & $-0,0197^{\star * *}$ & $-0,0428^{\star * *}$ & $-0,106^{* \star *}$ \\
\hline & $(0,00115)$ & $(0,00272)$ & $(0,00595)$ \\
\hline \multirow{2}{*}{ Anos de estudo } & $0,114^{\star \star \star}$ & $0,230^{\star \star \star}$ & $0,658^{\star \star \star}$ \\
\hline & $(0,00345)$ & $(0,00723)$ & $(0,0172)$ \\
\hline \multirow[t]{2}{*}{ Hábito cultural } & $0,411^{\star * *}$ & $0,761^{* * *}$ & $2,271^{* * *}$ \\
\hline & $(0,0160)$ & $(0,0308)$ & $(0,0898)$ \\
\hline \multirow[t]{2}{*}{ Renda per capita da UC } & $0,0000297^{\star \star *}$ & $0,0000525^{* * *}$ & $0,000159^{* * *}$ \\
\hline & $(0,00000369)$ & $(0,00000628)$ & $(0,0000237)$ \\
\hline $\begin{array}{l}\text { Efeito fixo de região } \\
\text { metropolitana }\end{array}$ & Sim & Sim & Sim \\
\hline Efeito fixo de tempo & Sim & Sim & Sim \\
\hline \multirow[t]{2}{*}{ Constante } & $-2,396^{* \star *}$ & $-4,347^{\star * *}$ & $-14,01^{* * *}$ \\
\hline & $(0,115)$ & $(0,238)$ & $(0,669)$ \\
\hline Observações & 126476 & 126476 & 126497 \\
\hline POF utilizadas & $\begin{array}{l}\text { 1987/88, 1995/96, } \\
2002 / 03 \text { e 2008/10 }\end{array}$ & $\begin{array}{l}\text { 1987/88, 1995/96, } \\
2002 / 03 \text { e 2008/11 }\end{array}$ & $\begin{array}{c}1987 / 88,1995 / 96,2002 / 03 \\
\text { e } 2008 / 12\end{array}$ \\
\hline
\end{tabular}

Nota: Modelos estimados conforme a Equação (1).

Erros padrões robustos clusterizados a nível das regiões metropolitanas em parênteses.

Pós Lei é uma dummy que assume valor 1 para o período após a criação da lei para cada região metropolitana.

Todas as regiões metropolitanas foram utilizadas para essas estimações.

* Estatisticamente significante a $10 \%$.

** Estatisticamente significante a 5\%.

${ }^{* * *}$ Estatisticamente significante a $1 \%$. 


\subsection{Resultados das estimações DDD}

Uma análise mais robusta sobre o efeito das leis de meia entrada pode ser feita utilizando mais um grupo controle: regiões metropolitanas que não passaram pelo tratamento no período de análise. Utilizando a abordagem DDD, a hipótese de identificação é que mudanças nas parcelas de consumidores de cultura, para o caso de variável resposta binária, e nos gastos com bens e serviços culturais, para o caso Tobit, não sejam sistematicamente diferentes entre as regiões metropolitanas. Dessa forma, pode-se pensar, como já discutido, no caso da disseminação do uso da internet ocorrida no período. Se a proporção de consumidores que desembolsam dinheiro em consumo de bens e serviços culturais diminui em função da oferta de cultura através de meios digitais e o surgimento da internet impactar especialmente os estudantes, as estimativas DD serão viesadas. Para as estimativas DDD, no entanto, o coeficiente estimado ainda seria o efeito tratamento se as mudanças causadas pelo surgimento da internet sobre o consumo de cultura de estudantes e não estudantes fossem semelhantes entre as regiões metropolitanas.

Assim como no caso das estimações DD, são realizadas estimações por grupos de regiões metropolitanas, em função da data da criação da lei. A Tabela (7) apresenta os resultados das estimações DDD pelos métodos Probit, Logit e Tobit para as regiões metropolitanas que tiveram a criação da lei entre o período 1988 e 1995. Como grupo controle de regiões metropolitanas, são utilizadas aquelas que não tinham lei de meia entrada no período 1995/96. Como grande parte desses estados criaram a lei de meia entrada no período de análise seguinte, a amostra é reduzida para apenas 1987/88 e 1995/96. O coeficiente de interesse é significativo a 5\% em todas as especificações, indicando que a meia entrada teve êxito em aumentar a probabilidade de consumo de bens e serviços culturais dos estudantes.

Com relação aos gastos com bens e serviços culturais, o coeficiente estimado indica que as leis de meia entrada causaram um aumento, em média, de $88 \%$ dos gastos dos estudantes com cultura. Embora esse valor seja considerável, vale ressaltar, novamente, que a média de gastos com cultura é muito baixa, cerca de $\mathrm{R} \$ 3,26$ durante o período de análise. Contudo, precisa se dizer que a magnitude desses coeficientes estimados pode estar viesada em função de possíveis efeitos das leis sobre os não estudantes, em caso de repasse de pre- 
ços por parte das firmas para o grupo não "beneficiado" pela meia entrada. Esta hipótese será checada mais adiante nas especificações que visam testar a robustez das estimativas aqui obtidas.

Tabela 7 - Coeficientes das estimações DDD para as regiões metropolitanas que tiveram a criação da meia entrada entre 1988 e 1995

\begin{tabular}{|c|c|c|c|}
\hline & \multicolumn{2}{|c|}{$\begin{array}{l}\text { Variável dependente: } 1 \text { se } 0 \\
\text { indivíduo consumiu bens } \\
\text { culturais e } 0 \text { caso contrário }\end{array}$} & \multirow{3}{*}{$\begin{array}{c}\text { Variável dependente } \\
\text { In(gastos com bens } \\
\text { serviços culturais) } \\
\text { Tobit } \\
\text { (3) }\end{array}$} \\
\hline & Probit & Logit & \\
\hline & (1) & (2) & \\
\hline \multirow[t]{2}{*}{ RM tratadas*Estudante*Pós lei } & $0,167^{\star *}$ & $0,321^{* *}$ & $0,883^{* *}$ \\
\hline & $(0,0752)$ & $(0,152)$ & $(0,405)$ \\
\hline \multirow[t]{2}{*}{ Estudante } & 0,0589 & 0,0867 & 0,236 \\
\hline & $(0,0444)$ & $(0,0814)$ & $(0,221)$ \\
\hline \multirow[t]{2}{*}{ Estudante*Pós lei } & $-0,0225$ & $-0,0364$ & 0,00607 \\
\hline & $(0,0174)$ & $(0,0484)$ & $(0,103)$ \\
\hline \multirow[t]{2}{*}{ RM tratadas*Estudante } & 0,0116 & 0,0315 & 0,107 \\
\hline & $(0,0920)$ & $(0,169)$ & $(0,481)$ \\
\hline \multirow[t]{2}{*}{ RM tratadas*Pós lei } & $-0,0102$ & $-0,0277$ & $-0,0642$ \\
\hline & $(0,115)$ & $(0,214)$ & $(0,644)$ \\
\hline \multirow[t]{2}{*}{ Homem } & $0,394^{* * *}$ & $0,784^{* * *}$ & $2,145^{\star \star *}$ \\
\hline & $(0,0202)$ & $(0,0418)$ & $(0,0949)$ \\
\hline \multirow[t]{2}{*}{ Idade } & $-0,0225^{\star * *}$ & $-0,0494^{* * *}$ & $-0,119^{\star \star *}$ \\
\hline & $(0,00160)$ & $(0,00397)$ & $(0,00861)$ \\
\hline \multirow[t]{2}{*}{ Anos de estudo } & $0,110^{* \star *}$ & $0,220^{* * *}$ & $0,624^{\star \star \star}$ \\
\hline & $(0,00373)$ & $(0,00814)$ & $(0,0176)$ \\
\hline \multirow[t]{2}{*}{ Hábito cultural } & $0,444^{* * *}$ & $0,818^{\star * \star}$ & $2,396^{* \star *}$ \\
\hline & $(0,0176)$ & $(0,0340)$ & $(0,0849)$ \\
\hline \multirow[t]{2}{*}{ Renda per capita da UC } & $0,0000223^{\star \star *}$ & $0,0000387^{\star \star *}$ & $0,000122^{* * *}$ \\
\hline & $(0,00000400)$ & $(0,00000707)$ & $(0,0000243)$ \\
\hline $\begin{array}{l}\text { Efeito fixo de região } \\
\text { metropolitana }\end{array}$ & Sim & Sim & Sim \\
\hline Efeito fixo de tempo & Sim & $\operatorname{Sim}$ & $\operatorname{Sim}$ \\
\hline \multirow[t]{2}{*}{ Constante } & $-2,311^{\star \star *}$ & $-4,124^{\star \star \star}$ & $-13,30^{\star \star \star}$ \\
\hline & $(0,117)$ & $(0,232)$ & $(0,665)$ \\
\hline Observações & 87948 & 87948 & 87948 \\
\hline POF utilizadas & $1987 / 88$ e $1995 / 96$ & $1987 / 88$ e $1995 / 96$ & $1987 / 88$ e 1995/96 \\
\hline
\end{tabular}

Nota: Modelos estimados conforme a equação (2).

Erros padrões robustos clusterizados a nível das regiões metropolitanas em parênteses.

Pós Lei é uma dummy que assume valor 1 para o período 1995/96.

As regiões metropolitanas tratadas são: Salvador, Fortaleza, Goiânia, Belo Horizonte, Belém, Recife, Rio de Janeiro capital e São Paulo.

As regiões metropolitanas utilizadas como grupo controle são: Brasília, Curitiba, Porto Alegre e Rio de Janeiro, excluindo a capital.

* Estatisticamente significante a 10\%.

** Estatisticamente significante a 5\%.

*** Estatisticamente significante a $1 \%$. 
A Tabela (8) apresenta as estimativas DDD para as regiões metropolitanas que tiveram a criação da meia entrada entre 1996 e 2003. Como grupo controle de regiões metropolitanas, são utilizadas aquelas que já haviam criado lei da meia entrada no período de análise anterior. ${ }^{11}$ Dessa forma, apenas utilizam-se as informações a partir da POF1995/96. Assim como no caso DD anterior, estimam-se os modelos tanto utilizando todas as informações posteriores a implementação das leis, quanto utilizando apenas uma POF após a criação das leis. Embora os coeficientes de interesse estimados sejam todos positivos, os resultados indicam que eles foram significativos a $5 \%$ apenas para o caso de amostra restrita a uma POF após a criação da meia entrada. Esse resultado sugere que a meia entrada teve efeito mais significativo de curto prazo. Através do modelo Tobit, tem-se a estimativa do efeito tratamento médio da lei sobre os gastos dos estudantes com bens culturais. Para o caso de amostra reduzida, sob a hipótese de que os diferenciais de tendências na ausência da criação da lei são similares entre as regiões metropolitanas, verifica-se que a meia entrada aumentou, em média, o consumo dos estudantes de bens culturais em $132 \%$.

${ }^{11}$ Essa escolha se justifica na medida em que apenas o Rio Grande do Sul teve lei posterior a 2003. 
Tabela 8 - Coeficientes das estimações DDD para as regiões metropolitanas que tiveram a criação da meia entrada entre 1996 e 2003

\begin{tabular}{|c|c|c|c|c|c|c|}
\hline & \multicolumn{4}{|c|}{$\begin{array}{l}\text { Variável dependente: } 1 \text { se o indivíduo consumiu } \\
\text { bens culturais e } 0 \text { caso contrário }\end{array}$} & \multicolumn{2}{|c|}{$\begin{array}{l}\text { Variável dependente: } \\
\text { In(gastos com bens e } \\
\text { serviços culturais) }\end{array}$} \\
\hline & Probit & Probit & Logit & Logit & Tobit & Tobit \\
\hline & (1) & (2) & (3) & (4) & (5) & (6) \\
\hline $\begin{array}{c}\mathrm{RM} \\
\text { tratadas*Estudante } \\
\text { *Pós lei }\end{array}$ & 0,167 & $0,201^{* *}$ & 0,349 & $0,418^{\star *}$ & 1,072 & $1,322^{\star \star \star}$ \\
\hline & $(0,154)$ & $(0,0930)$ & $(0,317)$ & $(0,202)$ & $(0,947)$ & $(0,179)$ \\
\hline Estudante & $\begin{array}{l}0,385^{* * *} \\
(0,0499)\end{array}$ & $\begin{array}{l}0,359^{\star \star *} \\
(0,0586)\end{array}$ & $\begin{array}{l}0,799^{\star * \star} \\
(0,108)\end{array}$ & $\begin{array}{l}0,755^{\star \star *} \\
(0,127)\end{array}$ & $\begin{array}{c}2,387^{* * *} \\
(0,318)\end{array}$ & $\begin{array}{l}2,310^{* \star *} \\
(0,0313)\end{array}$ \\
\hline Estudante*Pós lei & $\begin{array}{l}-0,0456 \\
(0,0466)\end{array}$ & $\begin{array}{l}-0,0254 \\
(0,0551)\end{array}$ & $\begin{array}{c}-0,153 \\
(0,0945)\end{array}$ & $\begin{array}{l}-0,118 \\
(0,108)\end{array}$ & $\begin{array}{l}-0,346 \\
(0,289)\end{array}$ & $\begin{array}{l}-0,244^{\star \star \star} \\
(0,0904)\end{array}$ \\
\hline$\frac{\mathrm{RM}}{\text { tratadas*Estudante }}$ & $316^{* *}$ & -0320 ** & $-0,614^{* *}$ & $-0,631^{* *}$ & $-1,969^{* *}$ & $-2,043^{* * *}$ \\
\hline & $(0,140)$ & $(0,132)$ & $(0,281)$ & $(0,272)$ & $(0,856)$ & $(0,114)$ \\
\hline RM tratadasPós lei & $\begin{array}{l}-0,224^{* *} \\
(0,105)\end{array}$ & $\begin{array}{l}-0,115 \\
(0,175)\end{array}$ & $\begin{array}{l}-0,447^{\star *} \\
(0,197)\end{array}$ & $\begin{array}{l}-0,231 \\
(0,336)\end{array}$ & $\begin{array}{l}-1,397^{\star *} \\
(0,641)\end{array}$ & $\begin{array}{l}-0,724^{* \star *} \\
(0,0457)\end{array}$ \\
\hline Homem & $\begin{array}{l}0,113^{\star \star \star} \\
(0,0233)\end{array}$ & $\begin{array}{l}0,141^{\star \star \star} \\
(0,0266)\end{array}$ & $\begin{array}{l}0,225^{\star \star *} \\
(0,0446)\end{array}$ & $\begin{array}{l}0,286^{* \star *} \\
(0,0509)\end{array}$ & $\begin{array}{l}0,767^{* \star *} \\
(0,148)\end{array}$ & $\begin{array}{l}0,969^{\star \star \star} \\
(0,00508)\end{array}$ \\
\hline Idade & $\begin{array}{l}-0,0175^{\star \star \star} \\
(0,00113)\end{array}$ & $\begin{array}{l}-0,0192^{* * *} \\
(0,00183)\end{array}$ & $\begin{array}{l}-0,0389^{* \star \star} \\
(0,00249)\end{array}$ & $\begin{array}{l}-0,0423^{* \star *} \\
(0,00398)\end{array}$ & $\begin{array}{l}-0,108^{\star \star \star} \\
(0,00734)\end{array}$ & $\begin{array}{l}-0,123^{\star \star \star} \\
(0,000311)\end{array}$ \\
\hline Anos de estudo & $\begin{array}{c}0,129^{\star * *} \\
(0,00329)\end{array}$ & $\begin{array}{l}0,125^{\star \star *} \\
(0,00304)\end{array}$ & $\begin{array}{l}0,275^{\star \star \star} \\
(0,00695)\end{array}$ & $\begin{array}{l}0,268^{\star * *} \\
(0,00628)\end{array}$ & $\begin{array}{l}0,830^{* * *} \\
(0,0205)\end{array}$ & $\begin{array}{l}0,835^{\star \star \star} \\
(0,00103)\end{array}$ \\
\hline Hábito cultural & $\begin{array}{l}0,366^{* * *} \\
(0,0143)\end{array}$ & $\begin{array}{l}0,401^{\star * *} \\
(0,0184)\end{array}$ & $\begin{array}{l}0,708^{\star \star \star} \\
(0,0313)\end{array}$ & $\begin{array}{l}0,766^{\star \star \star} \\
(0,0429)\end{array}$ & $\begin{array}{l}2,284^{\star \star \star} \\
(0,104)\end{array}$ & $\begin{array}{l}2,574^{* * *} \\
(0,0138)\end{array}$ \\
\hline $\begin{array}{c}\text { Renda per capita } \\
\text { da UC }\end{array}$ & $0,0000426^{\star \star *}$ & $0,0000413^{\star \star \star}$ & $0,0000744^{\star \star \star}$ & $0,0000724^{\star \star *}$ & $0,000262^{* * \star}$ & $0,000266^{\star \star *}$ \\
\hline & $(0,00000529)$ & $(0,00000595)$ & $(0,00000983)$ & $(0,0000115)$ & $(0,0000316)$ & $(0,00000151)$ \\
\hline $\begin{array}{l}\text { Efeito fixo de região } \\
\text { metropolitana }\end{array}$ & Sim & Sim & Sim & Sim & Sim & Sim \\
\hline Efeito fixo de tempo & Sim & Sim & Sim & Sim & Sim & Sim \\
\hline Constante & $\begin{array}{c}-2,310^{\star \star \star} \\
(0,114)\end{array}$ & $\begin{array}{c}-1,970^{* \star *} \\
(0,239)\end{array}$ & $\begin{array}{c}-4,330^{\star * *} \\
(0,243)\end{array}$ & $\begin{array}{c}-3,700^{\star \star *} \\
(0.451)\end{array}$ & $\begin{array}{c}-15,30^{\star \star \star} \\
(0,874)\end{array}$ & $\begin{array}{l}-53,50^{\star \star \star} \\
(0,00825)\end{array}$ \\
\hline Observações & 78123 & 58680 & 78123 & 58680 & 78144 & 58701 \\
\hline POF utilizadas & $\begin{array}{c}1995 / 96 \\
2002 / 03 \text { e } \\
2008 / 09\end{array}$ & $\begin{array}{l}1995 / 96 \text { e } \\
2002 / 03\end{array}$ & $\begin{array}{c}1995 / 96 \\
2002 / 03 \text { e } \\
2008 / 09\end{array}$ & $\begin{array}{l}1995 / 96 \text { e } \\
2002 / 03\end{array}$ & $\begin{array}{l}1995 / 96 \\
2002 / 03 \text { e } \\
2008 / 09\end{array}$ & $\begin{array}{l}1995 / 96 \text { e } \\
2002 / 03\end{array}$ \\
\hline
\end{tabular}

Nota: Modelos estimados conforme a Equação (2).

Erros padrões robustos clusterizados a nível das regiões metropolitanas em parênteses.

Póslei é uma dummy que assume valor 1 para o período maior ou igual a 2002/03.

As regiões metropolitanas tratadas são: Brasília, Curitiba e Rio de Janeiro, excluindo a capital.

As regiões metropolitanas utilizadas como grupo controle são: Salvador, Fortaleza, Goiânia, Belo Horizonte, Belém, Recife, Rio de Janeiro capital e São Paulo.

* Estatisticamente significante a $10 \%$.

** Estatisticamente significante a 5\%.

${ }^{* * *}$ Estatisticamente significante a $1 \%$. 


\subsection{Efeitos tratamento estimados}

Como já discutido, os coeficientes dos modelos Probit e Logit não fornecem o efeito tratamento médio das leis de meia entrada. É possível calcular, contudo, os efeitos tratamentos médios das leis de meia entrada para estudantes a partir do efeito incremental do coeficiente do termo de interação da regressão, conforme demonstrado por Puhani (2012). O efeito tratamento médio é dado pela média dos efeitos tratamentos de todas as observações. Conforme afirma Greene (2010), no entanto, essa não é a melhor forma de avaliar as implicações de uma política, na medida em que os efeitos são heterogêneos entre as observações. Dessa forma, no presente trabalho, além dos efeitos tratamento médios, calcula-se o efeito tratamento, a partir das estimações DDD, para o caso em que as covariadas tenham valores médios, para o primeiro quartil, último quartil e último decil de renda, para o primeiro e último quartil de idade e, por fim, para o primeiro e último quartil de escolaridade. Além disso, no apêndice do trabalho, encontram-se os gráficos das estimações dos efeitos tratamentos para diversos valores dessas covariadas. Os efeitos tratamento estimados pelos modelos Probit e Logit se encontram na Tabela (9). As colunas (1) e (2) referem-se às estimações para as regiões metropolitanas que tiveram a criação da meia entrada entre os anos de 1988 e 1995, enquanto as colunas (3), (4), (5) e (6) referem-se às estimações DDD para as regiões metropolitanas que tiveram a criação da meia entrada para estudantes entre os anos de 1996 e 2003.

Os resultados indicam que, para as mesmas amostras utilizadas, os efeitos estimados por Probit e Logit são semelhantes, o que já era esperado. Para as regióes metropolitanas que tiveram a criação da lei da meia entrada entre os anos de 1988 e 1995, o efeito tratamento médio é de 0,0206 e 0,0207 para os modelos Probit e Logit, respectivamente. Sob a hipótese de que mudanças nas tendências de consumo de cultura de estudantes e não estudantes não são sistematicamente diferentes entre regiões metropolitanas, esse resultado aponta que, para esse grupo, a meia entrada aumentou a probabilidade dos estudantes consumirem cultura, em média, em 2,1 pontos percentuais. Esse resultado é significativo a 5\% para o modelo estimado por Probit e a $10 \%$ para o modelo estimado por Logit. Quando o efeito tratamento é estimado para valores médios das covariadas, o resultado é um aumento, em média, de 1,5 e 1,2 pontos percentuais na 
probabilidade de estudantes consumirem bens e serviços culturais, estimados por Probit e Logit, respectivamente.

As evidências, portanto, sugerem uma diferença considerável entre os efeitos tratamento médio e na média das covariadas, indicando uma heterogeneidade dos efeitos entre os beneficiados. Quando se analisam os resultados com relação à renda per capita da UC, à idade e à escolaridade dos indivíduos, evidencia-se que a criação da meia entrada impacta principalmente os mais ricos, mais jovens e com mais anos de estudo. Esse resultado pode ser explicado pelo fato de que, embora a meia entrada reduza o preço dos bens e serviços culturais, esses bens ainda seriam caros para a média da população. Com relação à idade, as evidências podem ser explicadas pelo fato de que mudanças de preferências são mais comuns para indivíduos mais jovens e, assim, mesmo que as leis de meia entrada alterem preços relativos, indivíduos estudantes mais velhos não mudariam seus hábitos de consumo. Conforme já discutido, existe uma relação estreita entre consumo de bens culturais e escolaridade, sendo assim, pessoas com mais anos de estudo estariam mais sujeitas a serem impactadas pela criação das leis de meia entrada. Todas as fontes de heterogeneidades vão ao encontro dos resultados encontrados por Diniz e Machado (2011), que sugerem que idade, educação e renda são determinantes fundamentais dos gastos dos indivíduos com bens culturais.

Com relação às regiões metropolitanas que tiveram a criação de leis de meia entrada entre 1996 e 2003, os efeitos do tratamento só se mostram significativos, a 10\% de significância, para o caso de amostra reduzida, ou seja, utilizando apenas uma pesquisa depois da criação da meia entrada. Para essas estimações por Probit e Logit, a meia entrada ampliou, em média, a probabilidade de consumo de bens e serviços culturais em cerca de 2 pontos percentuais. Assim como no caso das regiões metropolitanas que tiveram a criação da meia entrada entre 1988 e 1995, o efeito tratamento estimado é maior para indivíduos com maior renda, maior escolaridade e mais jovens. Esses resultados também podem ser evidenciados nos gráficos presentes no apêndice do trabalho. 
Tabela 9 - Efeitos tratamento estimados da criação da meia entrada

\begin{tabular}{|c|c|c|c|c|c|c|}
\hline & \multicolumn{2}{|c|}{$\begin{array}{l}\text { Regiões metropolitanas } \\
\text { que tiveram a criação da } \\
\text { lei entre } 1988 \text { e } 1995\end{array}$} & \multicolumn{4}{|c|}{$\begin{array}{l}\text { Regiões metropolitanas que tiveram } \\
\text { a criação da lei entre } 1996 \text { e } 2003\end{array}$} \\
\hline & Probit & Logit & Probit & Probit & Logit & Logit \\
\hline \multirow[t]{2}{*}{ Efeito tratamento médio } & $0,0206^{\star *}$ & $0,0207^{\star}$ & 0,0171 & $0,0193^{*}$ & 0,0182 & $0,0204^{*}$ \\
\hline & $(0,00995)$ & $(0,0106)$ & $(0,0172)$ & $(0,00998)$ & $(0,0183)$ & $(0,0111)$ \\
\hline \multirow[t]{2}{*}{$\begin{array}{l}\text { Efeito tratamento para va- } \\
\text { lores médios das covariadas }\end{array}$} & $0,0149^{\star *}$ & $0,0121^{*}$ & 0,0111 & $0,0123^{*}$ & 0,00944 & $0,0104^{*}$ \\
\hline & $(0,00754)$ & $(0,00654)$ & $(0,0118)$ & $(0,00682)$ & $(0,00991)$ & $(0,00600)$ \\
\hline \multirow[t]{2}{*}{$\begin{array}{l}\text { Efeito tratamento para } 0 \\
\text { primeiro quartil de renda }\end{array}$} & $0,0199^{* *}$ & $0,0200^{\star *}$ & 0,0157 & $0,0176^{*}$ & 0,0166 & $0,0185^{\star}$ \\
\hline & $(0,00959)$ & $(0,0102)$ & $(0,0159)$ & $(0,00913)$ & $(0,0168)$ & $(0,0101)$ \\
\hline \multirow[t]{2}{*}{$\begin{array}{l}\text { Efeito tratamento para o } \\
\text { último quartil de renda }\end{array}$} & $0,0206^{\star \star}$ & $0,0207^{\star}$ & 0,0169 & $0,0191^{*}$ & 0,0179 & $0,0200^{*}$ \\
\hline & $(0,00996)$ & $(0,0106)$ & $(0,0171)$ & $(0,00991)$ & $(0,0180)$ & $(0,0109)$ \\
\hline \multirow[t]{2}{*}{$\begin{array}{l}\text { Efeito tratamento para o } \\
\text { último decil de renda }\end{array}$} & $0,0216^{\star \star}$ & $0,0217^{*}$ & 0,0188 & $0,0214^{*}$ & 0,0198 & $0,0222^{*}$ \\
\hline & $(0,0105)$ & $(0,0111)$ & $(0,0190)$ & $(0,0111)$ & $(0,0199)$ & $(0,0122)$ \\
\hline \multirow[t]{2}{*}{$\begin{array}{l}\text { Efeito tratamento para o } \\
\text { primeiro quartil de idade }\end{array}$} & $0,0259^{\star \star}$ & $0,0270^{* *}$ & 0,0209 & $0,0243^{\star *}$ & 0,0232 & $0,0269^{*}$ \\
\hline & $(0,0122)$ & $(0,0134)$ & $(0,0208)$ & $(0,0122)$ & $(0,0230)$ & $(0,0142)$ \\
\hline \multirow[t]{2}{*}{$\begin{array}{l}\text { Efeito tratamento para } 0 \\
\text { último quartil de idade }\end{array}$} & $0,0148^{\star}$ & $0,0137^{\star}$ & 0,0130 & $0,0144^{\star}$ & 0,0132 & $0,0145^{*}$ \\
\hline & $(0,00759)$ & $(0,00754)$ & $(0,0133)$ & $(0,00774)$ & $(0,0134)$ & $(0,00824)$ \\
\hline \multirow[t]{2}{*}{$\begin{array}{l}\text { Efeito tratamento para o } \\
\text { primeiro quartil de anos de } \\
\text { estudos }\end{array}$} & $0,0108^{\star \star}$ & $0,00965^{\star}$ & 0,00648 & $0,00822^{*}$ & 0,00575 & $0,00731^{*}$ \\
\hline & $(0,00548)$ & $(0,00523)$ & $(0,00692)$ & $(0,00454)$ & $(0,00604)$ & $(0,00419)$ \\
\hline \multirow{3}{*}{$\begin{array}{l}\text { Efeito tratamento para o } \\
\text { último quartil de anos de } \\
\text { estudos }\end{array}$} & & & & & & \\
\hline & $0,0279^{\star \star}$ & $0,0283^{\star \star}$ & 0,0261 & $0,0312^{* *}$ & 0,0284 & $0,0340^{*}$ \\
\hline & $(0,0134)$ & $(0,0144)$ & $(0,0262)$ & $(0,0159)$ & $(0,0285)$ & $(0,0184)$ \\
\hline Observações & 87948 & 87948 & 78123 & 58680 & 78123 & 58680 \\
\hline POF utilizadas & $\begin{array}{c}1987 / 88 \text { e } \\
1995 / 96\end{array}$ & $\begin{array}{c}1987 / 88 \text { e } \\
1995 / 96\end{array}$ & $\begin{array}{l}\text { 1995/96, } \\
2002 / 03 \text { e } \\
2008 / 09\end{array}$ & $\begin{array}{l}1995 / 96 \text { e } \\
2003 / 04\end{array}$ & $\begin{array}{l}\text { 1995/96, } \\
2002 / 03 \text { e } \\
2008 / 09\end{array}$ & $\begin{array}{l}1995 / 96 \\
\text { e 2003/04 }\end{array}$ \\
\hline
\end{tabular}

Nota: Erros padrões calculados a partir do método delta entre parênteses.

As colunas (1) e (2) dizem respeito as estimações das colunas (1) e (2), respectivamente, da Tabela (7), enquanto as colunas (3), (4), (5) e (6) são referentes as estimações realizadas nas colunas (1), (2), (3) e (4), respectivamente, da Tabela (8).

* Estatisticamente significante a $10 \%$.

** Estatisticamente significante a 5\%.

*** Estatisticamente significante a $1 \%$. 


\subsection{Checagem de robustez}

Para analisar os efeitos das leis meia entrada para estudantes sobre o consumo de cultura dos mesmos, utilizou-se como grupo controle os não estudantes. Entretanto, pode ser que os ofertantes de cultura, na presença da meia entrada para estudantes, repassaram aumentos de preços aos não estudantes. Se isso ocorrer de fato, os estimadores utilizados no presente trabalho podem estar superestimados, na medida em que captariam além do efeito positivo da meia entrada sobre o consumo dos estudantes, o efeito negativo sobre o consumo dos não estudantes. Para checar se isso realmente aconteceu, estima-se uma equação que permite a comparação do consumo de cultura de não estudantes residentes em regiões afetas pela meia entrada com o consumo de cultura de não estudantes residentes em regiões que não tiveram a criação de lei de meia entrada. Estima-se a seguinte equação cujas variáveis são as mesmas já descritas anteriormente:

$$
\begin{aligned}
& y_{i j t}=\alpha_{j}+\phi_{t}+\delta_{0} \text { PósLei }_{t} \cdot R M \text { tratada }_{j}+\gamma^{\prime} \text { Socioec }_{i j t}+\lambda^{\prime} E_{\text {Educ }} \text { ijt }+ \\
& \eta^{\prime} \text { Dem }_{i j t}+u_{i j t} \text {. }
\end{aligned}
$$

O coeficiente fornece o efeito da lei sobre os não estudantes no período, sob a hipótese de que na ausência do tratamento, as tendências de consumo dos não estudantes em diferentes regiões metropolitanas se manteriam as mesmas. Os coeficientes de interesse são apresentados na Tabela (10). Verifica-se que em grande parte das especificações, apesar de negativo, o coeficiente de interesse não é significativo. Para os modelos de variável resposta binária, apenas o Logit, para o caso de amostra completa e para as regiões metropolitanas que tiveram a criação da lei entre 1996 e 2003, coluna (6), se mostrou significativo a $10 \%$. Dessa forma, como não existe evidência robusta de que a meia entrada tenha alterado a probabilidade de consumo de cultura por parte dos não estudantes, as estimativas do presente trabalho podem ser interpretadas como relações causais sobre o grupo tratado, os estudantes.

Já com relação aos gastos com bens e serviços culturais, as estimativas presentes na Tabela (10) mostram que a meia entrada exerceu efeito negativo significativo sobre os gastos com cultura dos não estudantes para as regiões metropolitanas que tiveram a criação da lei entre 1996 e 2003. Dessa forma, os resultados anteriores das estimações Tobit para esse grupo de regiões metropolitana não podem 
ser tratados como efeitos causais sobre os estudantes. Esse resultado também explica as magnitudes elevadas dos efeitos encontrados através das estimações Tobit na Tabela (8), na medida em que o efeito tratamento captura tanto o aumento de gastos dos estudantes com bens culturais, quanto a redução dos gastos com esses bens pelos não estudantes.

Tabela 10 - Coeficientes das estimações DD para os não estudantes

\begin{tabular}{|c|c|c|c|c|c|c|c|c|c|}
\hline & \multicolumn{3}{|c|}{$\begin{array}{c}\text { Regiões metropolitanas que } \\
\text { tiveram a criação da lei entre } \\
1988 \text { e } 1995\end{array}$} & \multicolumn{6}{|c|}{$\begin{array}{l}\text { Regiões metropolitanas que tiveram a } \\
\text { criação da lei entre } 1996 \text { e } 2003\end{array}$} \\
\hline & $\begin{array}{l}\text { Probit } \\
\text { (1) }\end{array}$ & $\begin{array}{l}\text { Logit } \\
\text { (2) }\end{array}$ & $\begin{array}{l}\text { Tobit } \\
\text { (3) }\end{array}$ & $\begin{array}{l}\text { Probit } \\
\text { (4) }\end{array}$ & $\begin{array}{l}\text { Probit } \\
\text { (5) }\end{array}$ & $\begin{array}{l}\text { Logit } \\
(6)\end{array}$ & $\begin{array}{l}\text { Logit } \\
(7)\end{array}$ & $\begin{array}{l}\text { Tobit } \\
\text { (8) }\end{array}$ & $\begin{array}{l}\text { Tobit } \\
\text { (9) }\end{array}$ \\
\hline $\begin{array}{l}\text { RM } \\
\text { tratada* } \\
\text { Pós Lei }\end{array}$ & $\begin{array}{l}-0,0111 \\
(0,114)\end{array}$ & $\begin{array}{l}-0,0280 \\
(0,214)\end{array}$ & $\begin{array}{l}-0,0749 \\
(0,675)\end{array}$ & $\begin{array}{l}-0,184 \\
(0,116)\end{array}$ & $\begin{array}{l}-0,0827 \\
(0,161)\end{array}$ & $\begin{array}{l}-0,372^{*} \\
(0,220)\end{array}$ & $\begin{array}{l}-0,155 \\
(0,319)\end{array}$ & $\begin{array}{l}-0,311^{*} \\
(0,189)\end{array}$ & $\begin{array}{l}-0,152^{* \star *} \\
(0,0055)\end{array}$ \\
\hline Observações & 63949 & 63949 & 63949 & 56167 & 41742 & 56167 & 41742 & 56167 & 41742 \\
\hline POF utilizadas & $\begin{array}{l}\text { 1987/88 } \\
\text { e } 1995 / 96\end{array}$ & $\begin{array}{l}\text { 1987/88 } \\
\text { e } 1995 / 96\end{array}$ & $\begin{array}{c}1987 / 88 \\
\text { e } 1995 / 96\end{array}$ & $\begin{array}{c}1995 / 96 \\
2002 / 03 \\
\text { e 2008/09 }\end{array}$ & $\begin{array}{c}1995 / 96 \\
\text { e } 2003 / 04\end{array}$ & $\begin{array}{l}1995 / 96 \\
2002 / 03 \\
\text { e 2008/09 }\end{array}$ & $\begin{array}{l}1995 / 96 \\
\text { e 2003/04 }\end{array}$ & $\begin{array}{l}\text { 1995/96, } \\
2002 / 03 \\
\text { e 2008/09 }\end{array}$ & $\begin{array}{l}1995 / 96 \\
\text { e 2003/04 }\end{array}$ \\
\hline
\end{tabular}

Nota: Modelos estimados conforme a Equação (2)

Erros padrões robustos clusterizados a nível das regiões metropolitanas em parênteses.

As colunas (1) e (2) e (3) dizem respeito as estimações das colunas (1), (2) e (3), respectivamente, da Tabela (7), enquanto as colunas (4), (5), (6) e (7), (8) e (9) são referentes as estimações realizadas nas colunas (1), (2), (3), (4), (5) e (6), respectivamente, da tabela (8).

* Estatisticamente significante a $10 \%$.

** Estatisticamente significante a 5\%.

*** Estatisticamente significante a $1 \%$.

\section{Considerações finais}

A partir da abordagem da economia da cultura de que o consumo de bens e serviços culturais beneficia tanto seus consumidores quanto a sociedade como um todo, através da acumulação de capital cultural, estudar os efeitos das políticas públicas de incentivo a demanda por esses bens é fundamental. O objetivo deste trabalho foi, portanto, avaliar os efeitos da maior política de incentivo ao consumo de cultura existente no Brasil, as leis de meia entrada para estudantes. Para tanto, utilizou-se como fonte de dados todas as Pesquisas de Orçamento Familiar disponíveis. A análise, por uma questão de dis- 
ponibilidade de dados, foi realizada apenas para as regiões metropolitanas brasileiras.

A principal estratégia de identificação utilizada no presente trabalho foi a de Diferenças Triplas, a partir da estimação da probabilidade de consumo de cultura e dos gastos com esse tipo de bem. Sob a hipótese de que mudanças nas tendências de consumo de bens culturais para estudantes e não estudantes não sejam sistematicamente diferentes entre as regiões metropolitanas, os resultados encontrados pelo presente trabalho podem ser interpretados como relações causais da criação das leis de meia entrada para estudantes. Sob essa hipótese, portanto, os resultados sugerem que a política de incentivo à demanda logrou êxito em aumentar a probabilidade dos estudantes consumirem bens e serviços culturais em cerca de 2 pontos percentuais, em média, para as regióes metropolitanas que tiveram a aplicação da lei anterior a 1995. Apesar de semelhantes, quando se consideram as regiões metropolitanas que tiveram a criação da meia entrada posterior a 1996, os resultados não são robustos a diferentes especificações, evidenciando um efeito significativo da lei apenas no curto prazo. Os efeitos da meia entrada sobre a probabilidade de consumo de cultura dos estudantes, no entanto, não são homogêneos quando analisados por características de indivíduos. A lei parece ter afetado principalmente os estudantes mais jovens, com maior renda e maior escolaridade.

Por fim, no que diz respeito ao volume de gastos dos estudantes com bens e serviços culturais, há dois resultados distintos. Para as regiões metropolitanas que experimentaram criação de leis de meia entrada entre 1988 e 1995, as estimativas obtidas apontaram na direção de um aumento dos gastos dos estudantes com cultura. Já para as regiões metropolitanas que tiveram a criação de leis de meia entrada em períodos posteriores a 1996, as estimativas obtidas, embora positivas e significativas, não passaram pelos testes de robustez realizados neste estudo.

Este trabalho é, sob o nosso conhecimento, o primeiro a se dedicar em entender os efeitos das leis de meia entrada sobre o consumo. Em função de todas as razões que justificam o estudo dos efeitos das leis de meia entrada (comportamento das firmas no que tange a maximização dos lucros, a existência de preços diferenciados para estudantes em outros mercados, a possível existência de externa- 
lidades do consumo de cultura, e o tamanho do público-alvo das leis de meia entrada), mais estudos, teóricos e empíricos, tornam-se necessários. É preciso entender melhor os efeitos dessas leis principalmente sobre a lucratividade das empresas e as possibilidades de expansão da oferta (criação de novas empresas e geração de novos produtos e serviços) e sobre o consumo e o bem-estar dos grupos não beneficiários.

\section{Referências}

ATECA-AMESTOY, V. Cultural capital and demand. Economics Bulletin, v. 26, n. 1, p. 1-9, 2007.

ATECA-AMESTOY, V. Determining heterogeneous behavior for theater attendance. Journal of Cultural Economics, v. 32 n. 2, p 127-151, 2008.

BAUMOL, W. J., PANZAR, J. C. e WILling, R. D. Contestable Markets: An Uprising in the Theory of Industry Structure. The American Economic Review. v. 72, n. 1,p. 1-15, 1982

BORENSTEIN, S. Selling Costs and Switching Costs: Explaining Retail Gasoline Margins," The RAND Journal of Economics. v. 22, n.3, p. 354-369, 1991.

BOURDIEU, P. Cultural reproduction and social reproduction. In: Brown, Richard (Org.). Knowledge, Education, and Cultural Change: Papers in the Sociology of Education. Londres: Tavistock, 1973. p. 71-112.

COHEN, A. Package Size and Discrimination in Paper Towels. Working Papers University of Virginia, Department of Economics, 2000.

COURTY, P. e PAGLIERO, M. The Impact of Price Discrimination on Revenue: Evidence from the Concert Industry. The Review of Economics and Statistics. V.94, n.1, p.359-369, 2012.

DINIZ, S. C.; MACHADO, A. F. Analysis of the consumption of artistic-cultural goods and services in Brazil. Journal of Cultural Economics, v. 35, n. 1, p. 1-18, 2011.

FALCK, O.; FRITSCH, M.; HEBLICH, S. The phantom of the opera: Cultural amenities, human capital, and regional economic growth. Labour Economics, v. 18, n. 6, p. 755-766, 2011.

FARKAS, G. Cognitive skills and noncognitive traits and behaviors in stratification processes. Annual Review of Sociology. v. 29, n.1, p. 541-562, 2003.

FAULHABER, G. R. Cross-subsidization: pricing in public enterprises. The American Economic Review, V.65, p. 966-977, 1975.

FELTON, M.V. "On the Assumed Inelasticity of Demand for the Performing Arts", Journal of Cultural Economics. V. 16, n.1, p. 1-12, 1992.

GADDIS, S. M. The influence of habitus in the relationship between cultural capital and academic achievement. Social science Research, v. 42, n. 1, p. 1-13, 2013.

GAPINSKI, J. The Economics of Performing Shakespeare. The American Economic Review. V. 74, n.1, p. 458-466, 1984.

GREENE, W. Testing hypotheses about interaction terms in nonlinear models. Economics Letters, v. 107, n. 2, p. 291-296, 2010.

HOLMES, T. J. The effects of third-degree price discrimination in oligopoly. The American Economic Review, v. 79, n. 1, p. 244-250, 1989. 
HUNTINGTON, P.A.: Ticket Pricing Policy and Box Office Revenue. Journal of Cultural Economics, v. 17, n. 1, p. 71-87, 1993.

LAREAU, A., e HORVAT, E. M. Moments of social inclusion and exclusion race, class, and cultural capital in family-school relationships. Sociology of Education, v. 72, n.1, p. 37-53, 1999.

LESLIE, P. Price Discrimination in Broadway Theater. RAND Journal of Economics, v. 35, n. 3, p. 520-541, 2004.

LÉVY-GARBOUA, L. e MONTMARQUETTE, C. A Microeconometric Study of Theatre Demand. Journal of Cultural Economics, v.20, n.1,p. 25-50, 1996.

McMANUS, B. Nonlinear Pricing in an Oligopoly Market: the Case of Specialty Coffee. Working Paper, University of Virginia, Department of Economics, 2000.

MOORE, T. The Demand for Broadway Theatre Tickets. Review of Economics and Statistics. v. 48, n.1, p. 79-87, 1966.

PAGLIOTO, B. F.; MACHADO, A. F. Perfil dos frequentadores de atividades culturais: o caso nas metrópoles brasileiras. Estudos Econômicos, v. 42, n. 4, p. 701-730, 2012.

PORSSE, A. A.; VALIATI, L.; FLORISSI, S. (Org.). Economia da cultura: bem-estar econômico e evolução cultural. Porto Alegre: Ed. da UFRGS, 2007.

PUHANI, P. A. The treatment effect, the cross difference, and the interaction term in nonlinear differencein-differences models. Economics Letters, v. 115, n. 1, p. 85-87, 2012.

SCHMALENSEE, R. Output and welfare implications of monopolistic third-degree price discrimination. The American Economic Review, v. 71, n. 1, p. 242-247, 1981.

SEAMAN, B. Empirical studies of demand for the performing arts. Handbook of the economics of art and culture. Ed. Elsevier, v.1 p. 415-472, 2006.

SHEPARD, A. Price Discrimination and Retail Configuration. Journal of Political Economy, v. 99, n.1,p 30-53, 1991.

THROSBY, D. Cultural capital. Journal of Cultural Economics, v. 23, n. 1-2, p. 3-12, 1999.

THROSBY, D. Economics and culture. Cambridge: Cambridge University Press, 2000.

TRAMONTE, L.; WILLMS, J. D. Cultural capital and its effects on education outcomes. Economics of Education Review, v. 29, n. 2, p. 200-213, 2010.

VARIAN, H. R. Price discrimination and social welfare. The American Economic Review, v. 75, n. 4, p. $870-875,1985$. 


\section{Apêndice}

Conforme explicado na seção 4.3, as estimativas para os efeitos das leis de meia entrada apresentadas neste trabalho foram realizadas empregando a média para as covariadas. No entanto, é possível que o efeito tratamento seja diferente dependendo da renda do indivíduo, de sua escolaridade e de sua idade, por exemplo. Nesse anexo são apresentados os efeitos tratamento para diversos valores de cada uma dessas covariadas, ${ }^{12}$ mantendo as demais na média.

Nas Figuras 2 e 3, verifica-se que, para as regiões metropolitanas que tiveram a criação da meia entrada entre 1988 e 1995, o efeito tratamento é substancialmente maior para os mais jovens e de maior escolaridade. Percebe-se, também, um efeito maior entre os de maior renda per capita, porém em menor intensidade.
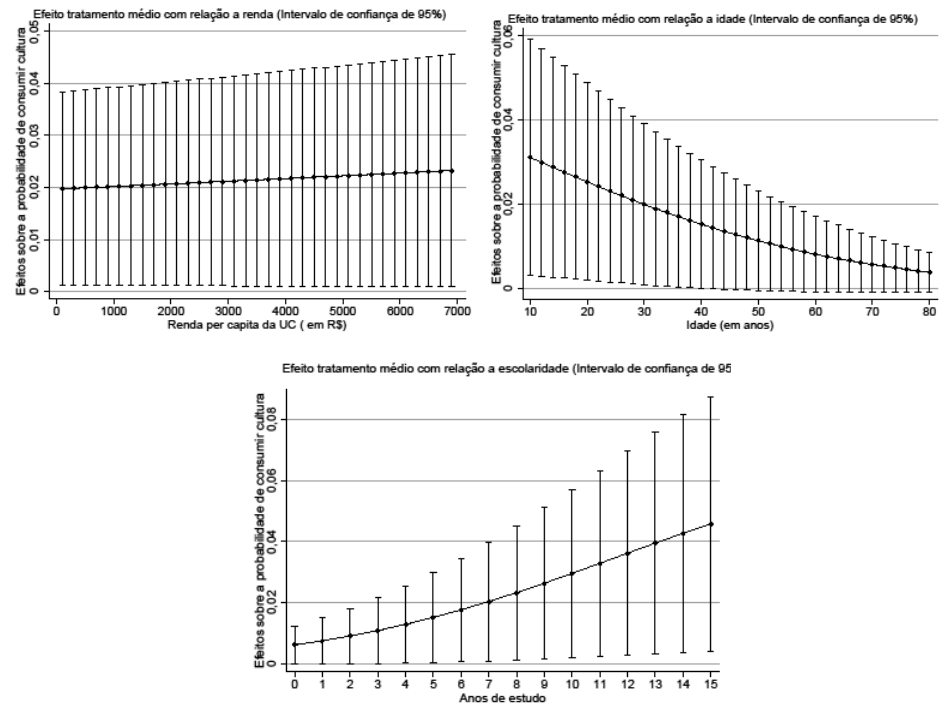

Figura 2 - Efeitos tratamento estimados por Probit para as regiões metropolitanas que tiveram a criação da lei entre 1988 e 1995.

Nota: Estimações DDD, conforme os resultados apresentados na coluna (1) da Tabela (7).

Fonte: Elaboração própria.

\footnotetext{
${ }^{12}$ Para os gráficos em relação à renda, estimam-se os efeitos tratamento para indivíduos com renda per capita domiciliar entre $\mathrm{R} \$ 100$ e $\mathrm{R} \$ 7000$, a cada $\mathrm{R} \$ 200$; para os gráficos com relação à idade, estimam-se os efeitos tratamento para indivíduos com idade entre 10 e 80 anos, por ano; para os gráficos com relação à escolaridade, estimam-se os efeitos tratamento para indivíduos com escolaridade de 0 a 15 anos de estudo, por ano de estudo.
} 

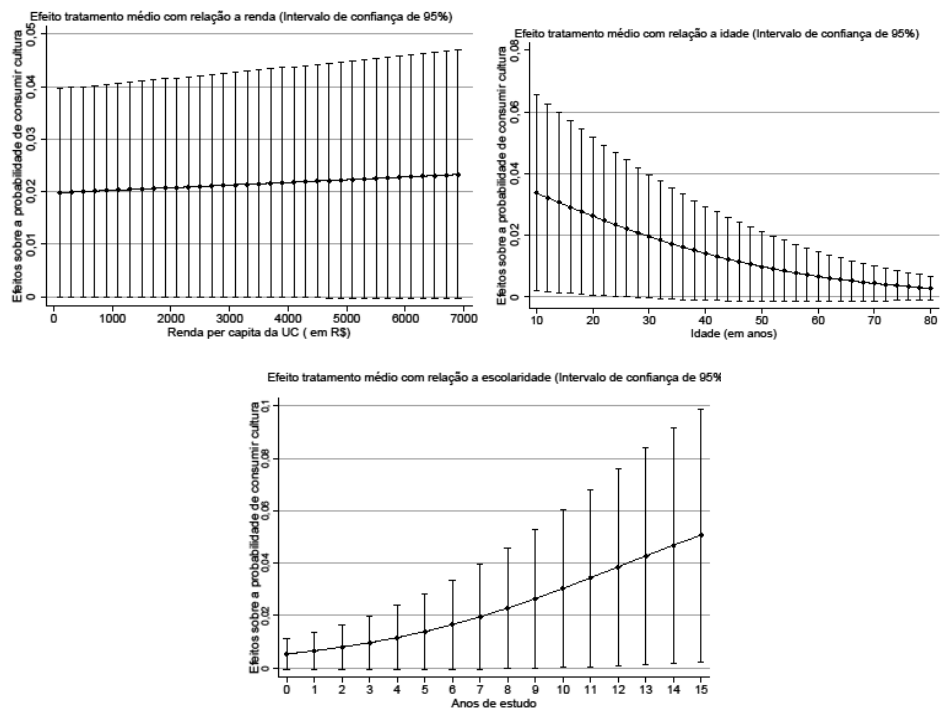

Figura 3 - Efeitos tratamento estimados por Logit para as regiões metropolitanas que tiveram a criação da lei entre 1988 e 1995.

Nota: Estimações DDD, conforme os resultados apresentados na coluna (2) da Tabela (7). Fonte: Elaboração própria.

De fato, se observa esse mesmo efeito para as Regiões Metropolitanas que tiveram a criação da meia entrada entre 1996 e 2003, com um efeito maior para os mais jovens e os de maior escolaridade, tanto quando se empregou a amostra completa (Figuras 4 e 5), quanto no caso em que se utilizou a amostra reduzida (Figuras 6 e 7$)$. 

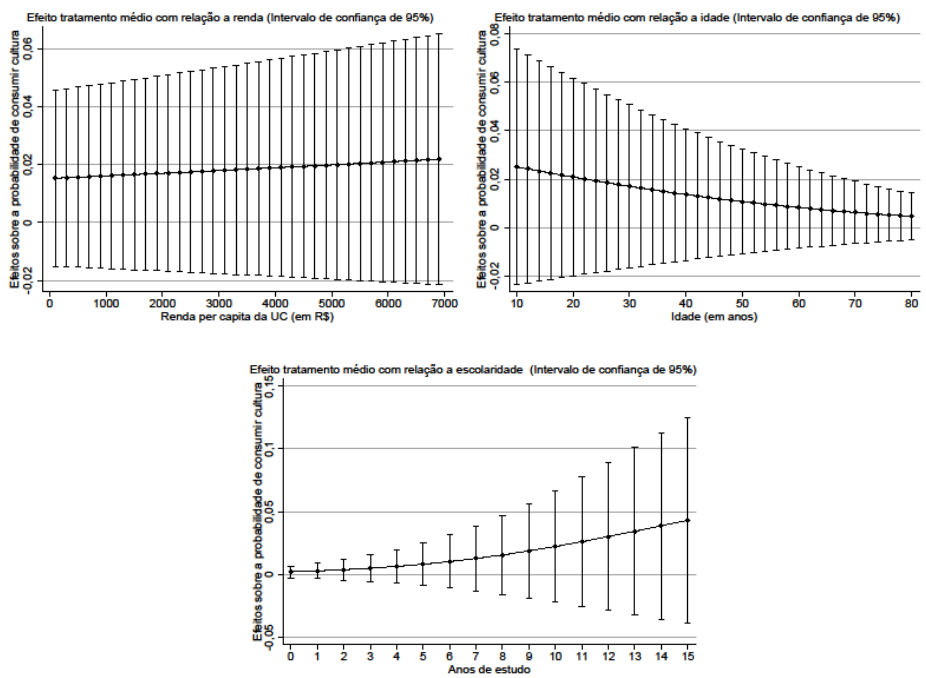

Figura 4 - Efeitos tratamento estimados por Probit para as regiões metropolitanas que tiveram a criação da lei entre 1996 e 2003 utilizando toda a amostra

Nota: Estimações DDD, conforme os resultados apresentados na coluna (1) da Tabela (8).

Fonte: Elaboração própria.
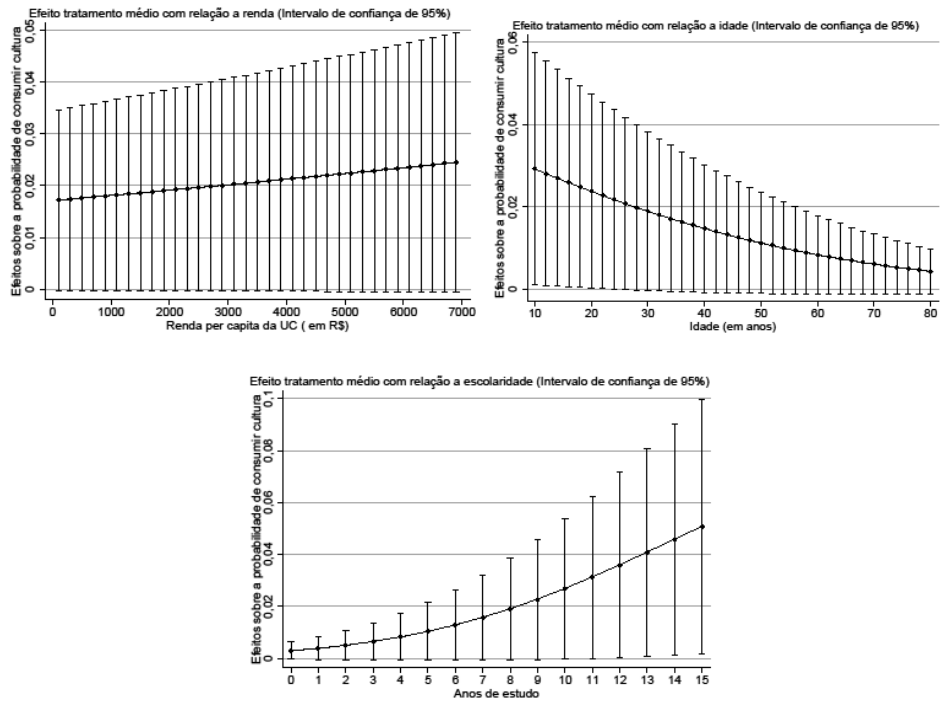

Figura 5 - Efeitos tratamento estimados por Probit para as regiões metropolitanas que tiveram a criação da lei entre 1996 e 2003 utilizando a amostra reduzida

Nota: Estimações DDD, conforme os resultados apresentados na coluna (2) da Tabela (8).

Fonte: Elaboração própria. 

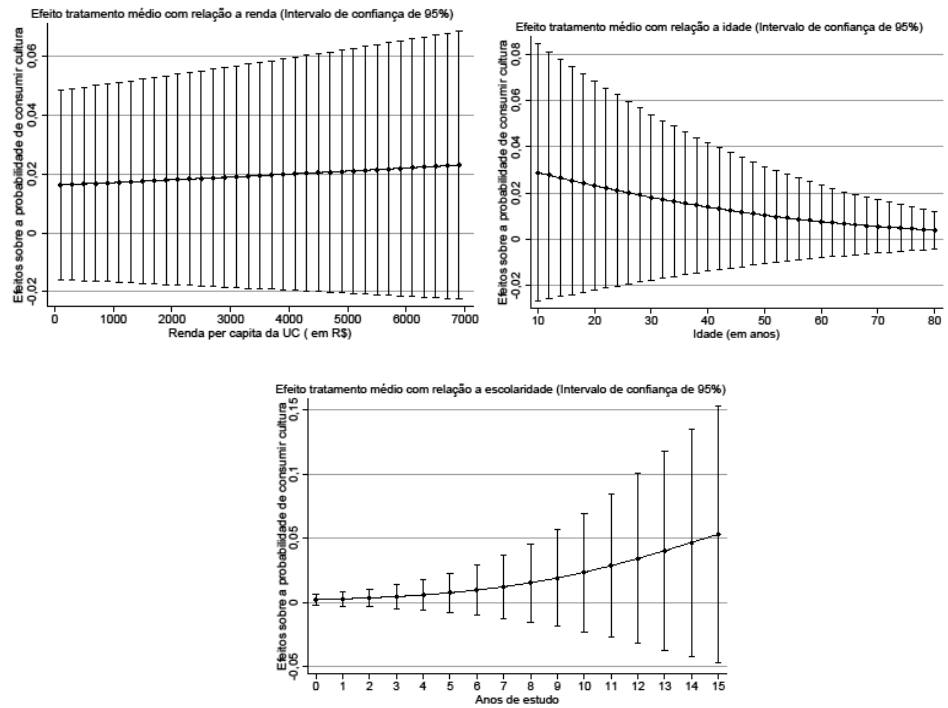

Figura 6 - Efeitos tratamento estimados por Logit para as regiões metropolitanas que tiveram a criação da lei entre 1996 e 2003 utilizando toda a amostra

Nota: Estimações DDD, conforme os resultados apresentados na coluna (3) da Tabela (8). Fonte: Elaboração própria.
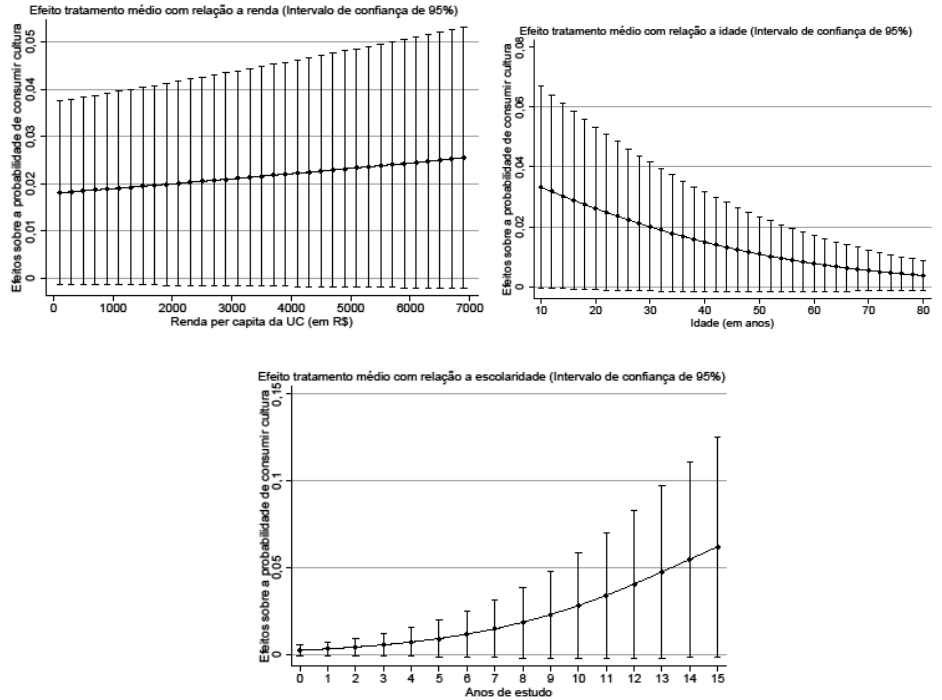

Figura 7 - Efeitos tratamento estimados por Logit para as regiões metropolitanas que tiveram a criação da lei entre 1996 e 2003 utilizando a amostra reduzida

Nota: Estimações DDD, conforme os resultados apresentados na coluna (4) da Tabela (8).

Fonte: Elaboração própria. 